\title{
Hierarchical Organization of Personality and Prediction of Behavior
}

\author{
Sampo V. Paunonen \\ University of Exeter
}

\begin{abstract}
Two studies evaluated personality trait measures and Big Five factor measures for their accuracy in predicting important behavior criteria. The results of both studies showed that the narrower traits and the broader factors, thought to define 2 levels of a hierarchy of personality variables, separately predicted most criterion variables. However, the incremental validity of the personality trait measures (the degree to which the traits increased the criterion prediction achieved by the factors) was generally much larger than the incremental validity of the Big Five factor measures. It was concluded that aggregating personality traits into their underlying personality factors could result in decreased predictive accuracy due to the loss of trait-specific but criterion-valid variance.
\end{abstract}

There is some intuitive appeal to the conceptualization that variables of personality are organized hierarchically, arranged according to the breadth of the behavior domains represented. One such model of personality is illustrated in Figure 1, first published by Eysenck (1947) and since cited by many others (e.g., Digman, 1990; Goldberg, 1993; Hampson, John, \& Goldberg, 1986; Paunonen, 1993). That model shows that, starting from the lowest level of the hierarchy, several specific responses or narrow behaviors of a person define a habitual response pattern, or a characteristic mode of behavior. Several such habitual response tendencies combine to form what is commonly called a personality trait. And it is a combination of these lower level traits that constitutes what is typically considered a broad factor of personality, residing at the top of the hierarchy.

The example of Figure 1 is a simplification, of course, because it illustrates the partial structure of only one personality factor, namely, Conscientiousness. Several such factors, each independent of the others, are generally thought necessary to describe the whole domain of human behavior. The example is also a simplification because it represents a nested model of personality, in which each component at each level of the hierarchy is connected to one and only one component above it. This exclusivity is undoubtedly unrealistic as a general rule; a personality trait, for example, could have theoretical and empirical associations with more than one personality factor.

A hierarchical model of personality, as exemplified in Figure 1 , raises a number of important questions. For example, what is the correct number of levels to the hierarchy? Four are shown in Figure 1, but a fifth level could easily be accommodated

Sampo V. Paunonen, Department of Psychology, Washington Singer Laboratories, University of Exeter, Exeter, England.

This research was supported by Social Sciences and Humanities Research Council of Canada Research Grants 410-91-1282 and 410-95-

1445. Some of the results of Study 1 were presented at the 101st Annual Convention of the American Psychological Association, August 1993, Toronto, Ontario, Canada.

Correspondence concerning this article should be addressed to Sampo V. Paunonen, who is now at Department of Psychology, University of Western Ontario, London, Ontario N6A 5C2, Canada. by, say, postulating that the higher level factors themselves are structured into a smaller number of superordinate dimensions. There has been some debate recently related to the number of levels of the hierarchy presumed to underlie human personality (e.g., see Cattell \& Krug, 1986; Costa \& McCrae, 1992a, 1992b; Eysenck, 1992a, 1992b; Hampson et al., 1986), but the issue seems far from being resolved. Much more empirical research in this area is needed.

A second question raised by the model of personality shown in Figure 1 is what is the exact organization of the hierarchy? This issue concerns the evaluation of so-called vertical and horizontal aspects of the hierarchy (Goldberg, 1993). There is the problem of identifying the number of factors that define the top level of the hierarchy, for instance, and identifying the specific traits that define each of those factors. Studies of this question have not been lacking. In fact, a substantial volume of recent empirical and theoretical work in the area of personality structure has pertained, in particular, to the evaluation of the organization of the upper two levels of the hierarchy represented in Figure 1. A consensus seems to have arisen among researchers, although it is hardly complete (e.g., see Block, 1995), that there are exactly five higher level factors of personality and, furthermore, that these factors are composed of traits and behaviors pertaining to (a) Extraversion, (b) Agreeableness, (c) Conscientiousness, (d) Neuroticism, and (e) Openness to Experience, respectively. (There is still some debate about the label to be applied to the last-named factor, with some researchers labeling it as Culture and others as Intellect.) These dimensions of behavior have come to be known collectively as the Big Five factors of personality (see reviews by Digman, 1990; John, 1990; McCrae \& John, 1992).

Yet another question raised by the model of Figure 1 asks, what are the relative empirical utilities of the different components of the hierarchy? This issue pertains largely to the measurement of individual differences on variables within the hierarchy and to the subsequent comparison of their ability to explain and to predict human behavior. Unfortunately, not much research has been devoted to answering this question directly. The present studies, however, were designed to address this shortcoming. 


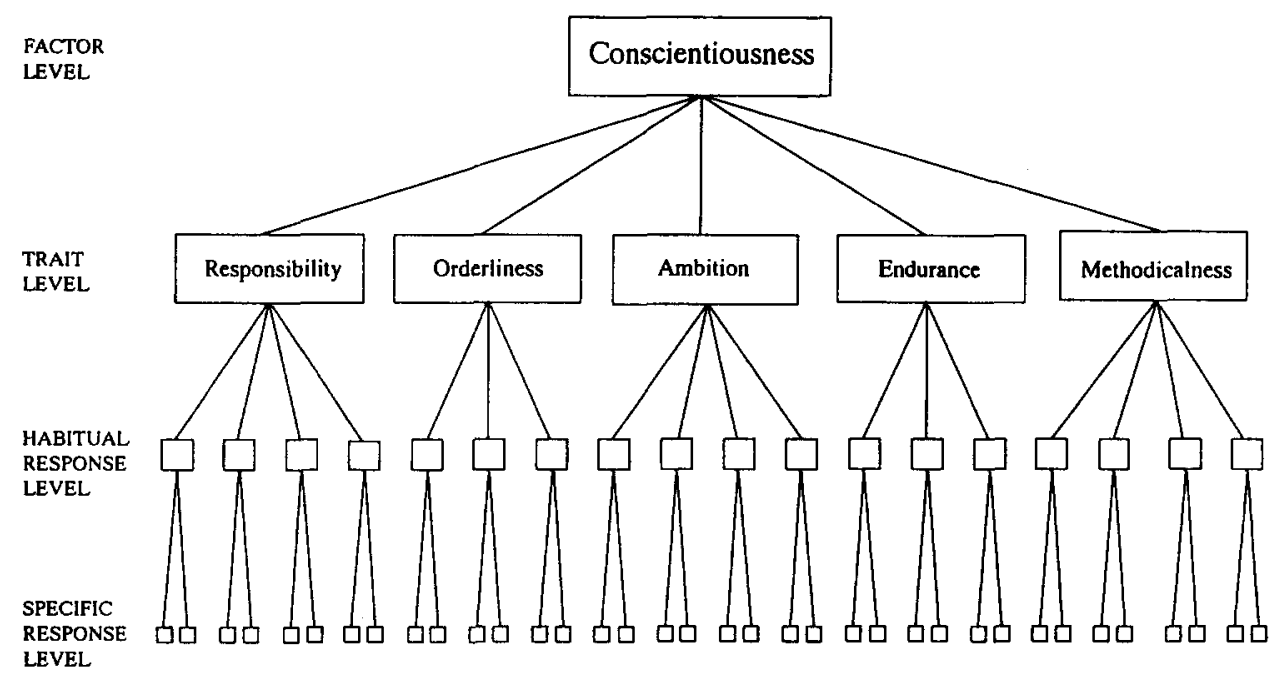

Figure 1. A hierarchical model of personality organization. From Dimensions of Personality by H. J. Eysenck, 1947, London: Routledge \& Kegan Paul.

\section{Relative Predictive Utility}

There are countless published studies demonstrating the criterion predictiveness of measures of lower level traits. There are also many studies showing the criterion predictiveness of measures of higher level factors of personality, such as the Big Five factors. Such evaluations are important for theoretical as well as practical reasons because they provide evidence of the measures' construct validities. Construct validity, however, refers to more than just a property of a psychometric instrument. As implied by the name, construct validation is intended not only to validate the measure of the construct but, pari passu, to verify the existence of the construct itself (Cronbach \& Meehl, 1955). Thus, failure to find theoretically expected evidence for the criterion predictiveness of one of the personality factors of the model illustrated in Figure 1, for instance, would be noteworthy; such a result could mean that the measure of the factor is unsound or that the construct itself is poorly conceptualized. In the latter case, serious misgivings would necessarily arise about the viability of the very model of personality on which the measure is based.

Although it is important to verify the criterion predictiveness of the separate components of any postulated personality hierarchy, there is also some value to determining the relative predictability of those components (Hampson et al., 1986). In terms of relative criterion predictiveness, it has been maintained that there is potentially some utility to measures of both narrow, lower level personality traits and broad, global personality dimensions. The former preserve variance specific to each individual measure, variance that might be predictive of specific criteria and that might be lost when the measures are combined into a higher level factor (e.g., Ashton, Jackson, Paunonen, Helmes, \& Rothstein, 1995; Costa \& McCrae, 1995; McCrae \& Costa, 1992; Paunonen, Jackson, Trzebinski, \& Forsterling, 1992; Paunonen, Rothstein, \& Jackson, in press). Measures of personality factors, on the other hand, are broader measures and contain variance that might better predict less specific, more multifaceted criteria, criteria that share variance with more than one of the lower level traits that constitute the factor (e.g., Costa \& McCrae, 1992c, 1995; McCrae \& Costa, 1992; Ones \& Viswesvaran, 1996). Direct empirical tests of these assumptions about relative predictiveness, however, have been scarce (cf. Ashton et al., 1995; Mershon \& Gorsuch, 1988; Ones, Schmidt, \& Viswesvaran, 1994).

The relative predictive superiority of the lower level traits and the higher level factors in the personality hierarchy is an issue that is of more than theoretical interest. If the broader personality dimensions have predictive advantages over their constituent narrower traits, one might rightly question the value of even measuring the latter, which are much greater in number. Perhaps the relatively few superordinate factors contain all the information about personality necessary to explain and predict human behavior adequately. Such a position has, it appears, a growing number of adherents in current personality theory.

Much of the literature on the Big Five factors of personality can be interpreted as suggesting that those five factors are the only variables necessary in describing, explaining, and assessing personality. Even a cursory glance at any contemporary personality journal will reveal numerous studies evaluating the personality correlates of various criteria, in which the only personality variables assessed are the Big Five factors. In the area of industrial-organizational psychology, for example, it has been claimed that the Conscientiousness factor of the Big Five accounts for most of the variation in worker performance due to personality, in almost all jobs (Barrick \& Mount, 1991; cf. Tett, Jackson, \& Rothstein, 1992).' If that is the case, then

\footnotetext{
'In fact, Ones et al. (1994) have taken that conclusion one step further, claiming that a very broad factor, derived as a linear combination of three of the Big Five factors and representing a construct they call integrity, is the personality dimension most responsible for overall job performance. Their analyses have led them to the observation that "in-
} 
measurement of the facets of Conscientiousness, such as orderliness, responsibility, and ambition, serves little more purpose than providing the raw building blocks out of which the higher level composite is constructed (e.g., Ones \& Viswesvaran, 1996).

\section{Overview of the Present Studies}

It has been argued that there are substantial benefits to be derived from the measurement of components at all levels of the personality hierarchy, beyond simply the top level. These benefits pertain to both the understanding and the prediction of behavior (e.g., Costa \& McCrae, 1995; Paunonen, 1993). The purpose of the two studies reported in this article was to verify this claim, in part, by comparing narrower, lower level trait measures with broader, higher level factor measures-Big Five measures in this case-in terms of their relative abilities at predicting a diverse set of criteria. If the factor-based personality measures predict criterion variables at least as well as do their trait-based constituents, then this would be consistent with the view that the variance common to the lower level measures, rather than the variance specific to those measures, is of paramount importance for behavior prediction (see Ones et al., 1994; Ones \& Viswesvaran, 1996). On the other hand, if the trait-based measures predict best, then this would support the argument that predictive losses can accrue when specific variance is discarded as traits are aggregated into their underlying broad factors (e.g., see Ashton et al., 1995; McCrae \& Costa, 1992).

\section{Criterion Selection}

In any study of the relative predictive merits of different classes of personality variables, the criteria used must be carefully considered. It might not be surprising to find a broad factor-based predictor outperforming a narrower trait-based predictor in estimating a broad factor-based criterion in which the factors underlying the predictor and criterion are the same. For example, a Big Five measure of Conscientiousness would probably predict peer ratings of overall conscientiousness better than would a relatively narrow trait measure of orderliness. By the same token, it might not be surprising to find the narrow orderliness trait measure outperforming the Conscientiousness factor measure in predicting a narrow trait-based criterion, such as ratings of bedroom neatness.

In deciding on the criteria to be used in the present studies, it was thought important to avoid those variables that are simply variants of the personality predictors used. Omitted were Big Five factor measures as the criteria for other measures of the same Big Five factors, or peer ratings on lower level traits as the criteria for self-ratings on the same traits. Instead, a clue was taken from some prediction studies done in the 1960s and 1970s by Goldberg and his associates (e.g., see Goldberg, 1972;

tegrity tests combine splinter factors of personality into a more meaningful superordinate grouping, achieving parsimony and superior prediction" (p. 33).
Hase \& Goldberg, 1967) and, more recently, by Mershon and Gorsuch (1988). Analogous to those studies, the criteria selected for the present research were ones that arguably have some social significance, such as smoking behavior, grade point average (GPA), and ratings of physical attractiveness. Such criteria are clearly not just variations of common personality traits or factors, such as those dimensions shown in Figure 1; instead, they are probably multifaceted, multidetermined variables sharing their variance with more than one domain of personality.

\section{Spurious Predictions}

Two studies are reported in this article, in which participants completed (a) several measures of lower level personality traits, (b) measures of the Big Five factors of personality, and (c) a Behavior Report Form, which contained the criterion measures. Analyses were designed to evaluate the relative utilities of the personality trait measures and the personality factor measures in predicting the criterion variables.

A statistical problem exists with empirical comparisons of the type described above, and it concerns the substantial imbalance in the number of predictors that belong to the different strata of the personality hierarchy. The fact that there are, by definition, more lower level traits than higher level factors means that there is a proportionally greater chance of finding personality predictors of the former kind that correlate significantly, but because of Type I error, with any criterion. One way around this problem is to cross-validate all prediction equations (see Goldberg, 1993). Another way is to select equal numbers of each type of predictor to study empirically (e.g., Ashton et al., 1995 ). Yet a third way is to use statistical procedures to ensure that the Type I error rate is the same for evaluations of predictor sets of different sizes. It was this latter approach to the problem of spurious predictions that was adopted in the two studies reported here.

\section{Study 1 \\ Method}

\section{Participants and Procedure}

A total of 96 undergraduate residents at a university dormitory (36 men and 60 women) volunteered for a study of personality in return for a cash stipend. Participants were 48 same-sex roommate pairs who had been living together for approximately 7 months. Their ages ranged from 18 to 21 years, with a mean of 19.2 .

Participants were tested in two sessions separated by 1 week. In the first session they completed a battery of self-report measures. In the second session the same measures were completed in a peer rating format, in which each participant was asked to describe the characteristics of his or her roommate. A small amount of missing data was handled using pairwise deletions in computing correlation and regression results. For example, one of the criteria pertained to number of traffic violations received, but 12 participants were nondrivers. Also, 3 participants did not complete a criterion measure pertaining to interest in fraternity membership, and 2 omitted a measure of dating variety.

\section{Personality Measures}

All of the participants completed measures of lower level personality traits and higher level personality factors, in both self-report and peer 
rating formats. However, only the self-ratings on the personality measures were used as predictors in this study.

The lower level trait measures of this study were those contained in Jackson's (1984) Personality Research Form-E (PRF). The PRF consists of 22 scales of 16 items each, which are responded to using truefalse endorsements. The scales used as predictors in the present study were Abasement, Achievement, Affiliation, Aggression, Autonomy, Change, Cognitive Structure, Defendence, Dominance, Endurance, Exhibition, Harmavoidance, Impulsivity, Nurturance, Order, Play, Sentience, Social Recognition, Succorance, Understanding, and Desirability. Omitted in the analyses was the Infrequency scale, which measures carelessness in responding to the items of the PRF.

The higher level personality factor measures used in this study were those of Costa and McCrae's (1992c) NEO Five Factor Inventory (NEOFFI). The NEO-FFI measures the Big Five factors of Extraversion, Agreeableness, Conscientiousness, Neuroticism, and Openness to Experience. Each scale has 12 items that are responded to on 5-point rating scales.

\section{Criterion Measures}

As mentioned earlier, the criteria for this study were chosen to represent variables of some social significance and variables that were not simply variants of the personality predictors used. These criterion measures were contained in the Behavior Report Form (see Figures 2 and 3 ), which each participant completed in both a self-report and a roommate-rating format. The two pages of the self-rating version of the Behavior Report Form are shown in Figures 2 and 3, respectively; the peer rating version differed only in the referent of the rating mentioned in each item (i.e., self or roommate).

Not all criterion variables measured were included in the analyses reported below. Although most of the items on the Behavior Report Form were fairly innocuous and straightforward ratings or objective statements of fact, a few items demanded a degree of impartiality on the part of a person rating him- or herself. Thus, because of possible impression management elicited by some of the more subjective judgments, it was decided to use peer ratings as the criterion data for the following variables: attractiveness, intelligence, popularity, and honesty. For the remaining variables, it was thought that self-reports would be the more accurate indices of behavior. A few of the self-report variables, however, had to be eliminated or transformed. First, the present sample's overall lack of participation in fraternities or sororities (only one participant belonged to a fraternity) meant that that variable had to be omitted from the criterion pool, and only the variable assessing interest in such membership was evaluated. Second, the masculinity-femininity selfratings and peer ratings correlated so highly with subject sex $(r=.68$ and $: 73$, respectively) that those ratings were also omitted from the criterion pool (sex was used as a covariate in the analyses that follow). Finally, the three frequency counts of different types of traffic violations were combined into one variable representing the mean number of all such violations per year of driving experience.

The final criterion pool was a total of 13 variables, of which 4 were based on peer ratings. These variables are listed below, along with their abbreviations (in parentheses) as used in the tables that follow: (a) grade point average (GPA); (b) number of dates per month (Datel); (c) number of different people dated per month (Date2); (d) smoking behavior rating (Smok1); (e) number of cigarettes smoked (Smok2); (f) choice of liberal arts or non liberal arts program of study (Arts); ( $\mathrm{g}$ ) interest in fraternity or sorority membership (Frat); (h) mean number of traffic violations per year (Viol); (i) self-rated religiosity (Relg); (j) roommate rating of physical attractiveness (Attr); $(\mathrm{k})$ roommate rating of intelligence (Intl); (1) roommate rating of popularity (Popl); and $(\mathrm{m})$ roommate rating of honesty (Hons). Sex of subject (Sex) was also used as a criterion in some analyses.

\section{Results and Discussion}

\section{Reliability of Measures}

The coefficient alpha reliabilities of the participants' responses to the 16-item PRF scales ranged from .59 (Desirability) to .91 (Order), with a mean of .77 . These values, shown in the last column of Table 1, are in line with those published in the PRF manual (Jackson, 1984). The reliabilities of the participants' ratings on the 12-item NEO-FFI scales, shown in the last row of Table 1, ranged from .75 (Openness to Experience) to .88 (Neuroticism), with a mean of .82 . The somewhat higher mean internal consistency for the NEO-FFI scales versus the longer PRF scales is probably due to the fact that the latter use true-false item endorsements, whereas the former use multiple category (5-point) ratings as responses (see Velicer, Govia, Cherico, \& Corriveau, 1985; Velicer \& Stevenson, 1978).

Unfortunately, the criterion measures could not be assessed for internal consistency reliability because each was a 1-item scale. Because of their short length, some of the criterion measures, especially those reflecting peer judgments, might be somewhat unreliable. On the other hand, despite their short length, other more objective criteria, such as the reports of GPA and number of cigarettes smoked per day, might be quite reliable.

\section{Predictor-Criterion Correlations}

The participants' lower level PRF trait scale scores and higher level NEO-FFI factor scale scores were first correlated with each other. Because of possible gender differences on some of the variables, however, it was necessary to partial participant gender out of those correlations. Otherwise, simple mean differences between the sexes in predictor variables could cause those variables to correlate in the mixed-sex sample, whereas they might not correlate in either single-sex sample. The resultant partial correlations are shown in Table 1. The pattern of values closely resembles that of other PRF-NEO correlations reported by Costa and McCrae (1988). (Those authors used the longer NEO-PI form in that study.)

The next analysis was to correlate the PRF and NEO-FFI scale scores with the criterion variables. As mentioned earlier, however, the universe of lower level personality traits outnumbers the universe of higher level personality factors. Even in this study, the former are represented by 21 PRF measures, whereas the latter by only 5 NEO-FFI measures. This means that there was a 4.2 times greater probability for the PRF scales of finding significant criterion predictions, by chance alone, than for the NEO-FFI scales. The solution to this problem used in this study was to evaluate the correlations for the lower level scales using a level of alpha, which sets the Type I error rate for each correlation, at about one fourth the level used for the higher level scales. Therefore, whereas the criterion correlations for the NEO-FFI predictors were assessed in terms of the usual $p=.05$ level of significance, the PRF predictors were evaluated in terms of a $p$ $=.0119$ level.

Lower level PRF predictors. The partial correlations (with participant gender removed) between the criteria and the PRF personality scale scores are shown in Table 2 . Perusing those 
Your Name:

Student Number:

Sex:

\section{Behavior Report Form}

INSTRUCTIONS. Please answer all of the questions below about you. Be as accurate as possible and do not omit any item.

1. How would you rate your level of physical attractiveness compared to the average student? Circle a number on the following scale:

\begin{tabular}{ccccccccc}
\multicolumn{2}{c}{ UNATTRACTIVE } & \multicolumn{3}{c}{ AVERAGE } & \multicolumn{3}{c}{ ATTRACTIVE } \\
1 & $\mathbf{2}$ & $\mathbf{3}$ & $\mathbf{4}$ & $\mathbf{5}$ & $\mathbf{6}$ & $\mathbf{7}$ & $\mathbf{8}$ & $\mathbf{9}$. \\
Extremely & Very & Moderately Somewhat & & Somewhat & Moderately & Very & Extremely
\end{tabular}

2. How would you rate your level of general intelligence compared to the average student? Circle a number on the following scale:

\begin{tabular}{ccccccccc}
\multicolumn{2}{c}{ UNINTELLIGENT } & & AVERAGE & \multicolumn{3}{c}{ INTELLIGENT } \\
$\mathbf{1}$ & $\mathbf{2}$ & $\mathbf{3}$ & $\mathbf{4}$ & $\mathbf{5}$ & $\mathbf{6}$ & $\mathbf{7}$ & $\mathbf{8}$ & $\mathbf{9}$ \\
Extremely & Very & Moderately & Somewhat & & Somewhat & Moderately & Very & Extremely
\end{tabular}

3. In relation to people you know, how would you describe your popularity among your peers?

\begin{tabular}{ccccccccc}
\multicolumn{3}{r}{ UNPOPULAR } & \multicolumn{3}{c}{ AVERAGE } & \multicolumn{3}{c}{ POPULAR } \\
$\mathbf{1}$ & $\mathbf{2}$ & $\mathbf{3}$ & $\mathbf{4}$ & $\mathbf{5}$ & $\mathbf{6}$ & $\mathbf{7}$ & $\mathbf{8}$ & $\mathbf{9}$ \\
Extremely & Very & Moderately Somewhat & & Somewhat Moderately & Very & Extremely
\end{tabular}

4. In relation to other people of your sex, how masculine/feminine are you?

\begin{tabular}{|c|c|c|c|c|c|c|c|c|}
\hline \multicolumn{3}{|c|}{ MASCULINE } & \multicolumn{3}{|c|}{ AVERAGE } & \multicolumn{3}{|c|}{ FEMININE } \\
\hline 1 & 2 & 3 & 4 & $\underline{5}$ & 6 & 7 & 8 & 9 \\
\hline xtremely & Very & Moderately & Somewhal & & Somewhat & Moderately & Very & Extremely \\
\hline
\end{tabular}

5. Would you consider yourself a religious person who, for example, might be interested in attending (or already does attend) formal religious services?

\begin{tabular}{ccccccccc}
\multicolumn{3}{c}{ NONRELIGIOUS } & \multicolumn{3}{c}{ AVERAGE } & \multicolumn{3}{c}{ RELIGIOUS } \\
$\mathbf{1}$ & $\mathbf{2}$ & $\mathbf{3}$ & $\mathbf{4}$ & $\mathbf{5}$ & $\mathbf{6}$ & $\mathbf{7}$ & $\mathbf{8}$ & $\mathbf{9}$ \\
Extremely & Very & Moderately Somewhat & & Somewhat Moderatcly & Very & Extremely
\end{tabular}

6. How would you describe your honesty compared to that of your friends?

\begin{tabular}{|c|c|c|c|c|c|c|c|c|}
\hline \multicolumn{3}{|c|}{ DISHONEST } & \multicolumn{3}{|c|}{ AVERAGE } & \multicolumn{3}{|c|}{ HONEST } \\
\hline 1 & 2 & 3 & 4 & $\underline{5}$ & 6 & 7 & 8 & 9 \\
\hline Extremely & Very & Moderatcly & Somewhat & & Somewhat & Moderately & Very & Extrenely \\
\hline
\end{tabular}

Figure 2. Page 1 of the Behavior Report Form, containing measures of the criterion variables.

correlations, one can see that the lower level traits were able to predict (at $p<.0119$ ) 10 of the 14 criteria (including participant gender). Criteria not predicted by any PRF scale were dating frequency, dating variety, and number of traffic violations. Also, the number of cigarettes smoked per day was not pre- dicted, although the smoking behavior rating was. Of the 21 traits listed in Table 2, 13 predicted some criterion. The 8 exceptions were the PRF scales of Abasement, Affiliation, Change, Cognitive Structure, Defendence, Dominance, Endurance, and Exhibition. 
7. Indicate your overall average grade for last year: $\%$ (percent)

8. Estimate the average number of dates per month that you have had this past year with someone of the opposite sex? (per month)

How many different people did you date over the course of the past year?

9. Do you consider yourself a nonsmoker, infrequent smoker, light smoker, moderate smoker, or heavy smoker? Circle a number below.

$\begin{array}{ccccc}1 & 2 & 3 & 4 & 5 \\ \text { Non- } & \begin{array}{c}\text { Infrequent } \\ \text { Smoker }\end{array} & \begin{array}{c}\text { Light } \\ \text { Smoker }\end{array} & \begin{array}{c}\text { Moderate } \\ \text { Smoker }\end{array} & \begin{array}{c}\text { Heavy } \\ \text { Smoker }\end{array}\end{array}$

If you smoke, how many cigarettes do you smoke a day on average? (per day)

10. If you had to choose one program of study (or, if you have already chosen one), which of the two below would you (did you) choose? Check one.

(1) _L_ Liberal Arts (Arts, Fine Arts, Humanities, etc.)

(2) __ Non-Liberal Arts (Natural Sciences, Social Sciences, Professional Schoois, etc.)

11. Are you currently a fraternity/sorority member or pledge? Check one.

(1) ___ no (2) ___ yes

If you are not currently a fraternity/sorority member or pledge, how much interest would you have in joining a fraternity/sorority?

\begin{tabular}{ccccccccc}
\multicolumn{2}{c}{ UNINTERESTED } & \multicolumn{3}{c}{ NEUTRAL } & \multicolumn{3}{c}{ INTERESTED } \\
1 & 2 & 3 & 4 & 5 & 6 & 7 & 8 & 9 \\
Extremely & Very & Moderately Somewhat & & Soncwhal Moderalcly & Very & Extremely
\end{tabular}

12. How long have you had a driver's license? Put 0 if never. (years)

If you have a driver's license:

How many speeding tickets have you had in the past?

How many parking tickets?

How many other traffic violations?

\section{STOP}

Figure 3. Page 2 of the Behavior Report Form, containing measures of the criterion variables.

Most of the significant predictor-criterion correlations in Table 2 are readily interpretable. For example, GPA was predicted by achievement striving $(r=.27)$ and low playfulness $(r=$ $-.27)$; smoking behavior was associated with individual differences in impulsivity $(r=.38)$ and orderliness $(r=-.30$, see also Smith, 1969); interest in fraternity membership was predicted by the need for social recognition $(r=.42)$; religiosity was related to the tendency to display nurturant behaviors $(r=$ .36); roommate perceptions of attractiveness were predicted by individual differences in participants' social desirability $(r=$
$.34)$; ratings of intelligence were associated with the need for understanding $(r=.27)$; and the women in the sample tended to be more harmavoidant $(r=.30)$, nurturant $(r=.47)$, sentient $(r=.32)$, and in need of succorance $(r=.34)$ than were the men. A few correlations, however, are less easily understood. For instance, it is not clear why peer ratings of honesty should be associated with their roommates' levels of nurturance ( $r=$ .38 ), especially given that participant gender was partialed out of these correlations.

Higher level NEO-FFI predictors. The partial correlations 
Table 1

PRF and NEO-FFI Scale Score Partial Correlations (Participant Gender

Removed) and Reliabilities

\begin{tabular}{|c|c|c|c|c|c|c|}
\hline \multirow[b]{2}{*}{ PRF scales } & \multicolumn{5}{|c|}{ NEO scales } & \multirow[b]{2}{*}{$\alpha$} \\
\hline & $\mathrm{E}$ & A & C & $\mathbf{N}$ & $\mathrm{O}$ & \\
\hline Abasement & $27 * *$ & $36 * *$ & -10 & 12 & -02 & 64 \\
\hline Achievement & 12 & -11 & $56 * *$ & 13 & $27 * *$ & 78 \\
\hline Affiliation & $67^{* *}$ & $27^{* *}$ & -06 & $-28 * *$ & 10 & 80 \\
\hline Aggression & -08 & $-71^{* *}$ & -06 & $28 * *$ & 03 & 74 \\
\hline Autonomy & $-37 * *$ & $-45^{* *}$ & -14 & -08 & 19 & 76 \\
\hline Change & 20 & $-22 *$ & -12 & -12 & $41 * *$ & 71 \\
\hline Cognitive Structure & -20 & -10 & $49 * *$ & $27 * *$ & $-23^{*}$ & 76 \\
\hline Defendence & -19 & $-53 * *$ & -03 & 20 & -18 & 72 \\
\hline Dominance & 13 & $-45 * *$ & 15 & -09 & $27 *$ & 90 \\
\hline Endurance & 13 & -16 & $46 * *$ & -10 & $27 * *$ & 77 \\
\hline Exhibition & $60 * *$ & -16 & 01 & -15 & $25^{*}$ & 86 \\
\hline Harmavoidance & $-26^{*}$ & $24 *$ & 13 & $27 * *$ & $-35^{* *}$ & 90 \\
\hline Impulsivity & $35 * *$ & -14 & $-50^{* *}$ & 03 & $30^{* *}$ & 79 \\
\hline Nurturance & $44 * *$ & $37 * *$ & 02 & 05 & $26^{*}$ & 81 \\
\hline Order & -17 & -04 & $62 * *$ & 17 & $-28 * *$ & 91 \\
\hline Play & $58 * *$ & $23 *$ & $-27 * *$ & $-28 * *$ & 08 & 64 \\
\hline Sentience & $32 * *$ & -05 & 13 & 10 & $57 * *$ & 67 \\
\hline Social Recognition & 15 & 10 & 09 & $47^{* *}$ & -06 & 84 \\
\hline Succorance & $29 * *$ & $32 * *$ & 07 & $30 * *$ & -13 & 81 \\
\hline Understanding & 03 & -09 & 06 & 01 & $48 * *$ & 75 \\
\hline Desirability & $36^{* *}$ & $24 *$ & $41^{* *}$ & $-50^{* *}$ & 20 & 59 \\
\hline$\alpha$ & 80 & 86 & 81 & 88 & 75 & \\
\hline
\end{tabular}

Note. $\quad$ Decimals are omitted. PRF $=$ Personality Research Form; NEO-FFI = NEO Five-Factor Inventory; $\alpha=$ coefficient alpha reliability; $\mathrm{E}=$ Extraversion; $\mathrm{A}=$ Agreeableness; $\mathrm{C}=$ Conscientiousness; $\mathrm{N}=$ Neuroticism; $\mathrm{O}=$ Openness to Experience.

${ }^{*} p<.05$. ** $p<.0119$.

(with participant gender removed) between the criteria and the NEO-FFI personality scores are shown in Table 3 . As did the PRF scales, the Big Five factors predicted 10 of the 14 criteria $(p<.05)$. The four exceptions were number of cigarettes smoked per day, choice of liberal arts or non liberal arts program of study, peer ratings of intelligence, and peer ratings of honesty. All five personality factors predicted some criterion, although Agreeableness and Neuroticism were most successful in this regard, each being associated with five criteria.

Some of the correlations shown in Table 3 are interpretable from a psychological perspective. Smoking behavior was predicted negatively by Conscientiousness $(r=-.29$, see also Ashton et al., 1995; Smith, 1969) and positively by Neuroticism ( $r=.25$ ); peer ratings of popularity were related to Extraversion $(r=.25)$, Agreeableness $(r=.24)$, and low Neuroticism $(r=-.34)$; and participant gender was predicted by Agreeableness $(r=.24)$ and Openness to Experience ( $r=.30$; with the women being higher than the men on these dimensions). Other predictor-criterion correlations, in contrast, were less easily explained. For instance, it is unclear why low Agreeableness should be associated with dating frequency $(r=-.23)$ and dating variety $(r=-.21)$ - the reverse would seem to be more understandable. It is also not entirely clear why low Agreeableness predicts high GPA $(r=-.24)$ or why Neuroticism is positively associated with religiosity $(r=.24)$ and interest in fraternity membership ( $r=.26$ ) and negatively associated with ratings of physical attractiveness $(r=-.32)$.

Partial set correlations. Cohen and Cohen's (1983) method of set correlation was next applied to the present data. Set correlation yields a single index of the amount of shared variance between a group of predictor variables and a group of criterion variables, being similar to canonical correlation analysis but without certain problems identified with the latter method ( see Cohen \& Cohen, 1983, pp. 489-490). When all PRF scales were used to predict all criterion variables simultaneously (with gender removed from both sets), the shrunken partial set correlation was $.84(p<.001)$. When the NEO-FFI scales were used to the same end, the shrunken partial set correlation was only .68 $(p<.001)$. The set of PRF scales, therefore, accounted for $24.2 \%$ more variance in the criteria as a whole than did the set of NEO-FFI scales.

\section{Predictors and Incremental Validity}

There is another method of evaluating the relative predictive merits of lower level trait measures and higher level factor measures, besides simply comparing predictor-criterion correlation coefficients. That method is to determine whether the one type of predictor accounts for variance in the criterion beyond that accounted for by the other type. To illustrate, the lower level 
Table 2

Partial Correlations (Participant Gender Removed) Between Criteria and Participants' PRF Scale Scores

\begin{tabular}{|c|c|c|c|c|c|c|c|c|c|c|c|c|c|c|}
\hline \multirow[b]{2}{*}{ PRF scale } & \multicolumn{14}{|c|}{ Criterion $^{\mathrm{a}}$} \\
\hline & GPA & Date1 & Date2 & Smok1 & Smok2 & Arts & Frat & Viol & Relg & Attr & Intl & Popl & Hons & $\operatorname{Sex}^{\mathrm{a}}$ \\
\hline Abasement & $-21^{*}$ & -13 & -13 & -03 & -10 & -03 & 02 & 04 & $26^{*}$ & -14 & -09 & 14 & 03 & -05 \\
\hline Achievement & $27 * *$ & 05 & -06 & -09 & -04 & -10 & 20 & 05 & $24^{*}$ & -06 & 09 & -04 & $23^{*}$ & 02 \\
\hline Affiliation & -20 & -09 & -02 & -03 & -03 & -08 & -02 & 00 & 03 & 01 & -14 & $22^{*}$ & 12 & 13 \\
\hline Aggression & 19 & 15 & 08 & $27^{* *}$ & $22 *$ & 20 & 05 & 09 & 02 & 06 & 01 & -09 & -02 & -18 \\
\hline Autonomy & 16 & 09 & 11 & 07 & 10 & $23 *$ & -14 & 01 & -10 & 05 & 20 & -17 & $-25^{*}$ & $-42 * *$ \\
\hline Change & -01 & -01 & 06 & 00 & -02 & 03 & -12 & 09 & 13 & 02 & -01 & -20 & -11 & $21^{*}$ \\
\hline Cognitive Structure & 19 & -07 & -03 & -08 & -03 & -18 & $21^{*}$ & -10 & 02 & -01 & 03 & -04 & 19 & 07 \\
\hline Defendence & $21 *$ & 11 & 06 & 14 & 17 & 06 & 04 & -08 & -19 & 10 & $22 *$ & -04 & 05 & -05 \\
\hline Dominance & 01 & 16 & 08 & 11 & 08 & 16 & 10 & 05 & 13 & 10 & 08 & -14 & 13 & -07 \\
\hline Endurance & 14 & 03 & 05 & -09 & -02 & -14 & 12 & 07 & 08 & 04 & 05 & 04 & 17 & -07 \\
\hline Exhibition & -15 & $23^{*}$ & 13 & $21 *$ & 11 & 12 & 14 & 16 & -02 & $21^{*}$ & -18 & 12 & -08 & 06 \\
\hline Harmavoidance & -01 & -06 & -17 & -03 & -13 & -01 & 20 & -01 & 07 & -12 & -12 & -02 & 10 & $30 * *$ \\
\hline Impulsivity & 02 & 10 & 13 & $38 * *$ & $25^{*}$ & $28 * *$ & -16 & 09 & -05 & -12 & -17 & 01 & -14 & -00 \\
\hline Nurturance & $-25^{*}$ & 01 & -18 & 04 & -02 & -05 & 16 & 07 & $36 * *$ & -05 & -19 & 13 & $38 * *$ & $47 * *$ \\
\hline Order & -11 & 01 & -06 & $-30 * *$ & $-23^{*}$ & -19 & 12 & 07 & 18 & 06 & -06 & -12 & 08 & 03 \\
\hline Play & $-27 * *$ & 01 & $24^{*}$ & 06 & -06 & -09 & -03 & 12 & -09 & 09 & -18 & $28 * *$ & -11 & -05 \\
\hline Sentience & -03 & -05 & 06 & 09 & 03 & 03 & 12 & $27 *$ & $25^{*}$ & -01 & 05 & 03 & 10 & $32 * *$ \\
\hline Social Recognition & 02 & 01 & 11 & 04 & -10 & -08 & $42 * *$ & 04 & 16 & -01 & -08 & -01 & -03 & 17 \\
\hline Succorance & 03 & 03 & -07 & 06 & -04 & -04 & -04 & -13 & 06 & -12 & -09 & 04 & 06 & $34 * *$ \\
\hline Understanding & 05 & -08 & -12 & 11 & 07 & 11 & 06 & 04 & $25^{*}$ & -09 & $27^{* * *}$ & -05 & 12 & $25 *$ \\
\hline Desirability & -07 & -08 & -05 & -18 & -06 & -18 & 07 & 04 & 02 & $34 * *$ & 08 & $32 * *$ & $24 *$ & 05 \\
\hline
\end{tabular}

Note. Decimals are omitted. PRF = Personality Research Form; GPA = grade point average; Date1 = dating frequency; Date2 = dating variety; Smok1 = smoking rating; Smok2 = smoking amount; Arts = liberal arts study; Frat = fraternity interest; Viol = traffic violations; Relg = religiosity; Attr = attractiveness; Intl = intelligence; Popl $=$ popularity; Hons $=$ honesty; Sex $=$ participant gender.

a Participant gender is not partialed.

$* p<.05$. ${ }^{* *} p<.0119$.

PRF scales can first be used to predict the criterion variables. Then, the Big Five factor scales can be added to the prediction equations to see whether they increase any of the correlations. The results would then be compared with those from the reverse situation, in which the factor scales are entered first into the prediction equations, and the lower level scales evaluated for their incremental contributions to predictive validity.

Tests of incremental validity are important in the present context because of the growing tendency of researchers to rely only on Big Five factor measures in personality prediction studies.
If the Big Five account for most of the variations in human behavior, then partialing those factors out of the lower level traits should leave little valid variance behind for criterion prediction. But if there is evidence of incremental validity to the trait measures, then one must question the belief that the common variance underlying the factors of personality is sufficient for optimal prediction. Such an outcome would imply that the specific variance of individual personality trait scales adds useful information to the understanding and prediction of behavior. A complementary interpretation would apply, of course, if the

Table 3

Partial Correlations (Participant Gender Removed) Between Criteria and Participants' NEO-FFI Scale Scores

\begin{tabular}{|c|c|c|c|c|c|c|c|c|c|c|c|c|c|c|}
\hline \multirow[b]{2}{*}{ NEO scale } & \multicolumn{14}{|c|}{ Criterion } \\
\hline & GPA & Date1 & Date2 & Smok1 & Smok2 & Arts & Frat & Viol & Relg & Attr & Intl & Popl & Hons & $\operatorname{Sex}^{\mathrm{a}}$ \\
\hline Extraversion & -15 & -03 & 09 & 03 & -01 & -03 & 06 & 14 & 04 & 11 & -18 & $25^{*}$ & 14 & 18 \\
\hline Agreeableness & $-24 *$ & $-23^{*}$ & $-21^{*}$ & -16 & -13 & -20 & 05 & -03 & -04 & -12 & -17 & $24 *$ & 16 & $24 *$ \\
\hline Conscientiousness & 06 & 03 & 04 & $-29 * *$ & -17 & -15 & 16 & 05 & 05 & 10 & 10 & -04 & 11 & 16 \\
\hline Neuroticism & 18 & 01 & 01 & $25 *$ & 10 & 13 & $26^{*}$ & 05 & $24 *$ & $-32 * *$ & -12 & $-34 * *$ & -03 & 18 \\
\hline Openness to Experience & 08 & 04 & -06 & $21^{*}$ & 15 & 18 & 19 & $25^{*}$ & 11 & 08 & 10 & 03 & 10 & $30^{* *}$ \\
\hline
\end{tabular}

Note. Decimals are omitted. NEO-FFI $=$ NEO Five-Factor Inventory; GPA = grade point average; Date1 = dating frequency; Date2 $=$ dating variety; Smok1 = smoking rating; Smok2 = smoking amount; Arts = liberal arts study; Frat = fraternity interest; Viol = traffic violations; Relg $=$ religiosity; Attr = attractiveness; Intl = intelligence; Popl = popularity; Hons = honesty; Sex = participant gender.

a Participant gender is not partialed.

$* p<.05$. ${ }^{* *} p<.0119$. 
factor-based personality measures were found to have incremental validity, adding to the criterion prediction of the lower level trait measures. In that case, the implication is that the variance underlying the factors adds something unique to prediction beyond that provided by the variance of the individual traits.

In the analyses reported below, the predictor-criterion partial correlations shown in Tables 2 and 3 were first corrected for attenuation in the predictors, using the reliabilities reported in Table 1. The set of PRF trait scales was then searched using stepwise regression for predictors of the criterion variables. Following that, the set of NEO-FFI measures of the Big Five factors was searched, again using stepwise regression, for scales that increased the degree of criterion prediction already achieved with the lower level predictors. The reverse case was also evaluated, in which the NEO-FFI factor scales were entered into the prediction equations first, followed by the PRF trait scales. It is important to note that the size of alpha used in deciding whether a predictor was statistically significant differed in these analyses according to the set of predictors being assessed. As in the correlational analyses, the NEO-FFI predictors were evaluated at $p<.05$, whereas the larger number of PRF predictors were evaluated at $p<.0119$. Furthermore, all multiple correlations reported have been corrected for shrinkage for the number of participants and predictors in the analyses.

Incremental validity of the NEO-FFI scales. The results of the first set of regression analyses are shown in Table 4 . Column 1 lists the multiple correlations (shrunken) with the criteria of any PRF scale( $s$ ) that added significantly $(p<.0119)$ to prediction (those scales' names and the signs of their corresponding regression weights are summarized in parentheses, and each multiple correlation is based on all significant predictors together in the regression equation). Column 2 of Table 4 shows the multiple correlations (shrunken) with the criteria of any NEO-FFI scale $(s)$ found to increase prediction $(p<.05)$ beyond that of any significant PRF predictors (where applicable). The last column in Table 4 reveals the percentages of criterion variance accounted for by the significant NEO-FFI predictors in the equations, after partialing out (participant gender and) the significant PRF predictors. These percentages indicate the size of the NEO-FFI scales' incremental validities in relation to the validities of the lower level trait measures.

Examination of Table 4 reveals that including lower level personality traits in the regression equations added substantially to criterion prediction in most cases. Of the 14 criteria, with gender partialed, 13 could be predicted significantly $(p<.0119)$ by participant standing on one or more of the PRF scales. Adding Big Five factor predictors to the equations further increased prediction $(p<.05$ ) of 7 of the 14 criteria. Thus, in those 7 cases, the personality factors were able to account for variance in the behavior criteria beyond that accounted for by the lower level personality traits. The mean additional criterion variance accounted for by the Big Five factors was $4.2 \%$, averaged across the 7 criterion variables, or $2.1 \%$ if averaged across all 14 criteria.

Table 4

Multiple Correlations $R$ (Shrunken) in Predicting Criterion Variables With PRF Scale Scores and NEO-FFI Scale Scores (Gender Partialed)

\begin{tabular}{llll}
\hline \multicolumn{1}{c}{ Criterion } & \multicolumn{1}{c}{ Predictor } \\
\cline { 2 - 3 } \multicolumn{1}{c}{ PRF $^{\mathrm{a}}$} & $\mathrm{PRF}+\mathrm{NEO}^{\mathrm{b}}$ & \% change \\
\hline Grade point average & $32(-\mathrm{Pl})$ & & \\
Dating frequency & & $21(-\mathrm{A})$ & $4.6^{*}$ \\
Dating variety & $40(+\mathrm{Pl},-\mathrm{Nu})$ & $44(-\mathrm{A})$ & $3.9^{*}$ \\
Smoking rating & $47(+\mathrm{Im},+\mathrm{Ag})$ & $50(+\mathrm{N})$ & \\
Smoking amount & $26(+\mathrm{Im})$ & & \\
Liberal arts study & $38(+\mathrm{Im},-\mathrm{Pl})$ & & $3.3^{*}$ \\
Fraternity interest & $60(+\mathrm{Sr},-\mathrm{Su},+\mathrm{Ac})$ & & $5.5^{* *}$ \\
Traffic violations & $32(+\mathrm{Se})$ & $53(+\mathrm{N})$ & $2.7^{*}$ \\
Religiosity & $50(+\mathrm{Nu},+\mathrm{Un},+\mathrm{Or})$ & $50(-\mathrm{A})$ & \\
Attractiveness & $44(+\mathrm{Dy})$ & $48(-\mathrm{N},-\mathrm{E})$ & \\
Intelligence & $41(+\mathrm{Un},+\mathrm{De})$ & $62(-\mathrm{C})$ & \\
Popularity & $60(+\mathrm{Pl},-\mathrm{Ch},+\mathrm{Dy})$ & & \\
Honesty & $49(+\mathrm{Cs},+\mathrm{Nu})$ & & \\
Sex & $58(+\mathrm{Nu},+\mathrm{Ha},+\mathrm{Ch})$ & & \\
\hline
\end{tabular}

Note. Decimals in $R$ values are omitted. PRF $=$ Personality Research Form; NEO-FFI $=$ NEO Five-Factor Inventory.

${ }^{a}$ Blank cell means no PRF scale significantly increased $R$ at $p<.0119$. Significant PRF scales are shown in parentheses: $\mathrm{Ac}=$ Achievement; $\mathrm{Ag}=$ Aggression; $\mathrm{Ch}=$ Change; $\mathrm{Cs}=$ Cognitive Structure; $\mathrm{De}=$ Defendence; $\mathrm{Ha}=$ Harmavoidance; $\mathrm{Im}=$ Impulsivity; $\mathrm{Nu}=$ Nurturance; $\mathrm{Pl}=\mathrm{Play} ; \mathrm{Se}=$ Sentience; $\mathrm{Sr}$ $=$ Social Recognition; $\mathrm{Su}=$ Succorance; $\mathrm{Un}=$ Understanding; $\mathrm{Dy}=$ Desirability.

${ }^{b}$ Blank cell means no NEO scale significantly increased $R$ at $p<.05$. Significant NEO scales are shown in parentheses: $\mathbf{A}=$ Agreeableness; $\mathrm{C}=$ Conscientiousness; $\mathrm{E}=$ Extraversion; $\mathrm{N}=$ Neuroticism.

${ }^{c}$ Percentage change in criterion variance accounted for by the addition of the NEO predictors to the PRF predictors.

${ }^{d}$ Participant gender is not partialed.

${ }^{*} p<.05$. ${ }^{* *} p<.0119$. 
Incremental validity of the PRF scales. In the next set of analyses, the order of variable entry into the prediction equations was changed from that described in the section above. The NEO-FFI scale scores were first included in the equations, in order to determine whether any personality factor could add to criterion prediction. Next, the PRF scale scores were included, assessing the incremental contributions of the lower level personality traits to the personality factors in prediction. The results of these analyses are shown in Table 5.

As can be seen in the first column of Table 5, the NEO-FFI scales added significantly $(p<.05)$ to the prediction of 11 of the 14 criteria. Moreover, adding the lower level PRF traits to the equations further increased the prediction $(p<.0119)$ of 12 of the 14 criteria. Note, however, in comparison with the analyses of the personality factors' incremental effects shown in Table 4, the relatively large percentages of additional criterion variance accounted for by the present lower level personality traits, averaging $15.7 \%$ across the 12 criterion variables, or $13.5 \%$ if averaged across all 14 criteria.

Bipartial set correlations. Set correlations were used again to determine the overlap between the PRF scales and the criterion variables and between the NEO-FFI scales and the criterion variables. On this occasion, however, bipartial set correlations (Cohen \& Cohen, 1983) were computed, in which one group of predictors was partialed from the other before computing predictor-criterion associations. Thus, the total amount of criterion variance accounted for by the NEO-FFI set of scales, above and beyond the PRF set, could be determined. This amount could then be compared with the amount accounted for by the PRF set over the NEO-FFI set. The shrunken bipartial set correlation between the criterion set (with gender partialed) and the NEO-FFI scales (with the PRF scales partialed) was .00. (Note that the correction for shrinkage can reduce an otherwise positive correlation to zero.) The corresponding value for the PRF scales (with the NEO-FFI scales partialed) was $.32(p<.05)$. Thus, considering the criterion set as a whole, the PRF scales were able to increase the criterion prediction of the NEO-FFI scales by about $10.2 \%$, whereas the NEO-FFI scales showed no such increment over the PRF.

Summary. It is worthwhile summarizing the results of the present regression analyses at this point. Both the variance of the personality factors and the variance of the personality traits separately predicted most of the individual criteria of this study. Moreover, removing either of these sources of variance out of the other still left residual variation that was predictive of many of those criteria. Partialing the variance due to the personality traits out of the Big Five predictors left variation in the latter that was correlated with several of the criteria, as seen in Table 4. And partialing the variance due to the personality factors out of the lower level predictors similarly left variation in those predictors that was correlated with many criteria, as seen in Table 5. Thus, both the narrow, lower level personality trait measures and the broad, higher level personality factor measures in this study demonstrated significant levels of incremental va-

Table 5

Multiple Correlations $R$ (Shrunken) in Predicting Criterion Variables With NEO-FFI Scale Scores and PRF Scale Scores (Gender Partialed)

\begin{tabular}{lllc}
\hline & \multicolumn{2}{c}{ Predictor } \\
\cline { 2 - 3 } \multicolumn{1}{c}{ Criterion } & \multicolumn{1}{c}{$\mathrm{NEO}^{\mathrm{a}}$} & \multicolumn{1}{c}{$\mathrm{NEO}+\mathrm{PRF}^{\mathrm{b}}$} & \% change \\
\hline Grade point average & $24(-\mathrm{A})$ & $36(+\mathrm{Ac})$ & $7.2^{* * *}$ \\
Dating frequency & $23(-\mathrm{A})$ & $41(+\mathrm{Pl})$ & $12.6^{* * *}$ \\
Dating variety & $20(-\mathrm{A})$ & $49(+\mathrm{Im})$ & $5.8^{* *}$ \\
Smoking rating & $43(-\mathrm{C},+\mathrm{N},+\mathrm{O})$ & $26(+\mathrm{Im})$ & $7.0^{* *}$ \\
Smoking amount & & $35(-\mathrm{En})$ & $5.8^{*}$ \\
Liberal arts study & $26(-\mathrm{A},+\mathrm{O})$ & $64(+\mathrm{Sr},-\mathrm{Su},+\mathrm{Au})$ & $27.8^{* * *}$ \\
Fraternity interest & $41(+\mathrm{N},+\mathrm{O},+\mathrm{C})$ & & \\
Traffic violations & $27(+\mathrm{O})$ & $53(+\mathrm{Nu},+\mathrm{Un},+\mathrm{Or})$ & $22.8^{* * *}$ \\
Religiosity & $24(+\mathrm{N})$ & $40(+\mathrm{Dy},+\mathrm{De})$ & $14.8^{* * *}$ \\
Attractiveness & $32(-\mathrm{N})$ & $60(+\mathrm{Dy},+\mathrm{De})$ & $16.6^{* * *}$ \\
Intelligence & & $49(+\mathrm{Nu},+\mathrm{Cs})$ & $20.0^{* * *}$ \\
Popularity & $40(-\mathrm{N},+\mathrm{A})$ & $60(-\mathrm{Au},+\mathrm{Ch},+\mathrm{Ha})$ & $23.7^{* * *}$ \\
Honesty & & $24.5^{* * *}$ \\
Sex & & & \\
\hline
\end{tabular}

Note. Decimals in $R$ values are omitted. NEO-FFI $=$ NEO Five-Factor Inventory; PRF $=$ Personality Research Form.

${ }^{a}$ Blank cell means no NEO scale significantly increased $R$ at $p<.05$. Significant NEO scales are shown in parentheses: $\mathrm{A}=$ Agreeableness; $\mathrm{C}=$ Conscientiousness; $\mathrm{N}=$ Neuroticism; $\mathrm{O}=$ Openness to Experience. ${ }^{b}$ Blank cell means no PRF scale significantly increased $R$ at $p<.0119$. Significant PRF scales are shown in parentheses: $\mathrm{Ac}=$ Achievement; $\mathrm{Au}=$ Autonomy; $\mathrm{Ch}=$ Change; $\mathrm{Cs}=$ Cognitive Structure; $\mathrm{De}=$ Defendence; $\mathrm{En}=$ Endurance; $\mathrm{Ha}=$ Harmavoidance; $\mathrm{Im}=$ Impulsivity; $\mathrm{Nu}=$ Nurturance; $\mathrm{Pl}=\mathrm{Play} ; \mathrm{Sr}$

$=$ Social Recognition; Su = Succorance Un = Understanding; Dy = Desirability.

${ }^{c}$ Percentage change in criterion variance accounted for by the addition of the PRF predictors to the NEO predictors.

${ }^{d}$ Participant gender is not partialed.

$* p<.05$. ${ }^{* *} p<.0119$. $* * * p<.001$. 
lidity relative to each other. The incremental validity of the personality trait predictors, however, was generally much higher than that of the personality factor predictors.

\section{Study 2}

Method

\section{Overview}

Study 2 was designed to test the generality of the criterion predictiveness results of Study 1 by extending those findings to new personality variables. Although the same higher level personality factor predictors were used in this study as in the first study (i.e., the Big Five), the lower level trait predictors were different.

\section{Participants and Procedure}

A total of 92 undergraduate residents at a university dormitory (28 men and 64 women who had not participated in Study 1) volunteered for a study of personality in return for a cash stipend. Participants were 46 same-sex roommate pairs who had been living together for approximately 7 months. Their ages ranged from 17 to 24 years, with a mean of 19.2. As in Study 1, participants were tested in two sessions separated by 1 week. In the first session they completed a battery of self-report measures. In the second session the same measures were completed in a peer-rating format, in which each participant was asked to describe the characteristics of his or her roommate.

\section{Personality Measures}

All of the participants completed measures of lower level personality traits and higher level personality factors, in both self-report and peerrating formats. As in Study 1, only the self-ratings on the personality measures were used as predictors.

The lower level trait measures of this study were those contained in the Jackson Personality Inventory (JPI; Jackson, 1976). The JPI consists of 16 scales of 20 items each, which are responded to using true-false endorsements. The scales used as predictors in this study were Anxiety, Breadth of Interest, Complexity, Conformity, Energy Level, Innovation, Interpersonal Affect, Organization, Responsibility, Risk Taking, SelfEsteem, Social Adroitness, Social Participation, Tolerance, and Value Orthodoxy. Omitted in the analyses was the JPI Infrequency scale, which measures carelessness in responding to the questionnaire. Apart from their names, most JPI trait scales are manifestly different in content from the PRF scales used in Study 1. Whereas the latter constructs represent 20 variables in the tradition of Murray (1938), the former represent measures derived from the more recent research in individual differences (see Jackson, 1976, 1994; Paunonen \& Jackson, 1996).

The higher level personality factor measures used in this study were the same as those used in Study 1, namely, the NEO-FFI scales of Extraversion, Agreeableness, Conscientiousness, Neuroticism, and Openness to Experience (Costa \& McCrae, 1992c).

\section{Criterion Measures}

The criterion measures used in this study were, to maintain comparability, the same as those used in Study 1. Thus, the Behavior Report Form (Figures 2 and 3 ) was administered to participants in both selfreport and peer-rating formats. The specific variables analyzed and reported below are those already referred to in the Results and Discussion section of Study 1.

\section{Results and Discussion}

\section{Reliability of Measures}

The coefficient alpha reliabilities of the participants' truefalse responses to the 20-item JPI scales ranged from .61 (Social Adroitness) to .91 (Conformity), with a mean of .79. These values, shown in the last column of Table 6, are consistent with those published for the JPI (Jackson, 1977, 1994). The reliabilities of the participants' 5-point ratings of the 12-item NEO-FFI scales, shown in the last row of Table 6 , ranged from .68 (Openness to Experience) to .85 (Conscientiousness), with a mean of .77. The comparable mean alpha coefficients for the two questionnaires suggests that the attenuation in reliability due to the shorter length of the NEO-FFI scales was compensated for by the increase in reliability due to its use of multiple category ratings as responses.

\section{Predictor-Criterion Correlations}

The lower level JPI trait scale scores and the higher level NEO-FFI factor scale scores were first correlated with each other. Those correlations, with gender partialed, are shown in Table 6 . The personality scales were then correlated with the criteria. As in Study 1, those correlations, reported below, were evaluated at the $p<.05$ level for the 5 NEO-FFI scales, but at a reduced level for the 15 JPI scales $(p<.0167)$.

Lower level JPI predictors. The partial correlations (with participant gender removed) between the criteria and the JPI personality scale scores are shown in Table 7. Examining those correlations, one can see that the lower level traits were able to predict $(p<.0167$ ) 11 of the 14 criteria. Not predicted were participants' GPA, dating frequency, and peer ratings of their popularity. Of the 15 JPI traits, all but 1 predicted some criterion, the exception being Social Adroitness.

Most of the significant personality trait-criterion correlations shown in Table 5 are meaningful from a theoretical point of view. For instance, the number of different people dated was negatively related to the need for closeness and affect in interpersonal relations ( $r=-.36$ ); the number of cigarettes smoked was positively correlated with risk-taking behavior $(r=.37)$, and the smoking behavior rating was negatively correlated with the need for conformity $(r=-.41)$; choice of liberal arts study was associated with a preference for cognitive complexity ( $r=$ $.28)$ and with tolerance for others $(r=.29)$; the students' interests in fraternity membership were related to their levels of conformity ( $r=.33$ ); self-rated religiosity was predicted by a personality variable pertaining to having orthodox or conventional values ( $r=.47$ ); participants who received the higher roommate ratings of intelligence generally showed the higher levels of cognitive complexity $(r=.30)$; and the women students tended to be higher than the men on behaviors related to interpersonal affect $(r=.33)$, organization $(r=.26)$, and responsibility ( $r=.40$ ). A few of the predictor-criterion correlations, in contrast, are less interpretable. It is not immediately clear why the number of traffic violations was predicted by individual differences in the tolerance of others $(r=.34)$; why attractiveness ratings were associated with low breadth of interest $(r=-.27)$, low energy level $(r=-.33)$, and low organiza- 
Table 6

JPI and NEO-FFI Scale Score Partial Correlations (Participant Gender

Removed) and Reliabilities

\begin{tabular}{lcccccc}
\hline & \multicolumn{7}{c}{ NEO scale } \\
\cline { 2 - 7 } \multicolumn{1}{c}{ JPI scale } & $\mathrm{E}$ & $\mathrm{A}$ & $\mathrm{C}$ & $\mathrm{N}$ & $\mathrm{O}$ & $\alpha$ \\
\hline Anxiety & -01 & -04 & 10 & $68^{* *}$ & -03 & 81 \\
Breadth of Interest & 20 & -12 & 17 & -15 & $68^{* *}$ & 83 \\
Complexity & -03 & $-22^{*}$ & 04 & -12 & $62^{* *}$ & 71 \\
Conformity & -12 & $36^{* *}$ & 01 & $39^{* *}$ & $-26^{*}$ & 91 \\
Energy Level & $23^{*}$ & -05 & $33^{* *}$ & $-30^{* *}$ & $39^{* *}$ & 83 \\
Innovation & 17 & $-28^{* *}$ & -07 & -04 & $50^{* *}$ & 88 \\
Interpersonal Affect & $28^{* *}$ & 17 & -01 & $29 * *$ & 04 & 81 \\
Organization & -17 & 07 & $61^{* *}$ & 12 & -01 & 73 \\
Responsibility & 12 & $36^{* *}$ & $24^{*}$ & 00 & 00 & 74 \\
Risk Taking & 09 & $-41^{* *}$ & -13 & 07 & $24^{*}$ & 86 \\
Self Esteem & $50^{* *}$ & $-25^{*}$ & 15 & $-40^{* *}$ & $25^{*}$ & 89 \\
Social Adroitness & -04 & -19 & -14 & 16 & 14 & 61 \\
Social Participation & $44^{* *}$ & 11 & 01 & 07 & $-24^{*}$ & 83 \\
Tolerance & 05 & $25^{*}$ & 12 & -19 & $25^{*}$ & 68 \\
Value Orthodoxy & -01 & 15 & -03 & 19 & $-27^{*}$ & 78 \\
\multicolumn{1}{c}{$\alpha$} & 70 & 79 & 85 & 84 & 68 & \\
\hline
\end{tabular}

Note. Decimals are omitted. JPI = Jackson Personality Inventory; NEO-FFI = NEO Five-Factor Inventory; $\alpha=$ coefficient alpha reliability; $\mathrm{E}=$ Extraversion; $\mathrm{A}=$ Agreeableness; $\mathrm{C}=$ Conscientiousness; $\mathrm{N}=$ Neuroticism; $\mathrm{O}=$ Openness to Experience.

${ }^{*} p<.05 . \quad{ }^{* *} p<.0167$

tion $(r=-.30)$; or why peer perceptions of honesty were negatively correlated with a preference for innovation $(r=$ $-.26)$.

Higher level NEO-FFI predictors. The partial correlations (with participant gender removed) between the criteria and the NEO-FFI personality scores are shown in Table 8 . The Big Five factors predicted 7 of the 14 criteria $(p<.05)$. Those significant correlations are largely interpretable: The number of cigarettes

Table 7

Partial Correlations (Participant Gender Removed) Between Criteria and Participants' JPI Scale Scores

\begin{tabular}{|c|c|c|c|c|c|c|c|c|c|c|c|c|c|c|}
\hline \multirow[b]{2}{*}{ JPI scale } & \multicolumn{14}{|c|}{ Criterion } \\
\hline & GPA & Date1 & Date2 & Smok1 & Smok2 & Arts & Frat & Viol & Relg & Attr & Intl & Popl & Hons & $\operatorname{Sex}^{a}$ \\
\hline Anxiety & 20 & -01 & $-29 * *$ & 02 & -07 & -04 & 02 & 08 & $22 *$ & -04 & -05 & -01 & $22 *$ & $23 *$ \\
\hline Breadth of Interest & 08 & 14 & 20 & $33^{* *}$ & $23 *$ & 17 & 00 & -11 & -06 & $-27^{* *}$ & 06 & $-23^{*}$ & $-24 *$ & 10 \\
\hline Complexity & 22 & -03 & 16 & $35 * *$ & $34 * *$ & $28^{* *}$ & 11 & -08 & -14 & -15 & $30^{* *}$ & -16 & -05 & 21 \\
\hline Conformity & 05 & 09 & -07 & $-27^{*}$ & $-41 * *$ & -15 & $33^{* *}$ & 02 & $24^{*}$ & 04 & -09 & 20 & 14 & 01 \\
\hline Energy Level & 11 & 04 & 14 & 03 & -03 & 03 & 05 & $-26^{*}$ & -01 & $-33^{* *}$ & 09 & -17 & $-22 *$ & 05 \\
\hline Innovation & -03 & 06 & 17 & $24^{*}$ & 13 & $28 * *$ & 02 & -11 & -12 & -15 & 02 & -11 & $-26 * *$ & -02 \\
\hline Interpersonal Affect & 20 & -03 & $-36 * *$ & 19 & $23^{*}$ & 01 & -02 & -03 & 06 & 00 & -08 & 04 & $24 *$ & $33 * *$ \\
\hline Organization & 19 & -08 & -06 & -20 & -14 & -12 & $26^{*}$ & 07 & -01 & $-30 * *$ & -10 & -15 & -08 & $26 * *$ \\
\hline Responsibility & $23 *$ & 02 & 03 & -08 & 01 & 18 & -05 & -12 & -02 & -11 & 12 & -07 & 10 & $40^{* *}$ \\
\hline Risk Taking & -09 & 07 & 18 & $37 * *$ & $23 *$ & 10 & 08 & -01 & -04 & -04 & -02 & -02 & -16 & $-22^{*}$ \\
\hline Self-Esteem & 00 & 13 & 16 & $46^{* *}$ & $48^{* *}$ & 07 & -14 & -07 & -20 & 04 & 08 & 02 & -07 & $22 *$ \\
\hline Social Adroitness & -11 & 11 & 13 & -03 & -13 & -04 & 17 & 18 & 21 & -14 & -06 & -14 & -13 & -08 \\
\hline Social Participation & 05 & 17 & -03 & $26 *$ & 22 & -14 & 16 & 08 & -05 & 09 & -13 & 15 & 13 & $33^{* *}$ \\
\hline Tolerance & 13 & 02 & 07 & 17 & $29 * *$ & $29 * *$ & -09 & $-34 * *$ & -06 & -09 & $21^{*}$ & 03 & -06 & -08 \\
\hline Value Orthodoxy & 11 & -07 & -01 & -19 & $-23^{*}$ & -13 & 12 & 15 & $47^{* *}$ & -06 & 08 & 02 & 19 & $23^{*}$ \\
\hline
\end{tabular}

Note. Decimals are omitted. JPI = Jackson Personality Inventory; GPA = grade point average; Date1 = dating frequency; Date2 = dating variety; Smok1 = smoking rating; Smok2 = smoking amount; Arts = liberal arts study; Frat = fraternity interest; Viol = traffic violations; Relg = religiosity; Attr = attractiveness; Intl = intelligence; Popl = popularity; Hons = honesty; Sex = participant gender.

${ }^{a}$ Participant gender is not partialed.

$* p<.05 .{ }^{* *} p<.0167$. 
Table 8

Partial Correlations (Participant Gender Removed) Between Criteria and Participants' NEO-FFI Scale Scores

\begin{tabular}{|c|c|c|c|c|c|c|c|c|c|c|c|c|c|c|}
\hline \multirow[b]{2}{*}{ NEO scale } & \multicolumn{14}{|c|}{ Criterion } \\
\hline & GPA & Date 1 & Date2 & Smok1 & Smok2 & Arts & Frat & Viol & Relg & Attr & Int 1 & Popl & Hons & $\operatorname{Sex}^{a}$ \\
\hline Extraversion & -02 & 05 & 08 & $24 *$ & $26^{* *}$ & -06 & 00 & -22 & -06 & 08 & 09 & 18 & 03 & $25^{* * *}$ \\
\hline Agreeableness & 03 & -04 & -09 & -14 & -09 & 07 & 08 & -17 & 12 & 10 & 02 & $27 * *$ & 09 & 14 \\
\hline Conscientiousness & 20 & -19 & -09 & -21 & -12 & -16 & 15 & -15 & 00 & $-32 * *$ & 01 & -08 & 02 & $33^{* *}$ \\
\hline Neuroticism & 03 & 02 & -20 & -15 & -17 & -01 & 06 & 13 & 17 & -07 & -08 & 01 & 10 & 06 \\
\hline Openness to Experience & 19 & 16 & 04 & $32 * *$ & $28^{* *}$ & 21 & -04 & 03 & $-24^{*}$ & -20 & 15 & -17 & $-24 *$ & 06 \\
\hline
\end{tabular}

Note. Decimals are omitted. NEO-FFI = NEO Five-Factor Inventory; GPA = grade point average; Date1 = dating frequency; Date2 = dating variety; Smok1 = smoking rating; Smok2 = smoking amount; Arts = liberal arts study; Frat $=$ fraternity interest; Viol = traffic violations; Relg = religiosity; Attr = attractiveness; Intl = intelligence; Popl = popularity; Hons = honesty; Sex = participant gender.

${ }^{a}$ Participant gender not partialed.

$* p<.05$. $\quad{ }^{* *} p<.0167$.

smoked and the smoking behavior rating were both predicted by Extraversion ( $r=.24$ and .26 , respectively) and by Openness to Experience ( $r=.32$ and .28 , respectively); self-rated religiosity was related to low Openness to Experience ( $r=-.24$ ); the greater the students' rated popularity, in general, the greater their Agreeableness $(r=.27)$; and the women in the study were generally higher than the men in Conscientiousness $(r=.33)$. Less clear were the negative correlations between peer ratings of honesty and the targets' levels of Openness to Experience ( $r$ $=-.24$ ) and between peer perceptions of attractiveness and individual differences in the participants' Conscientiousness ( $r$ $=-.32$ ). Note, however, that the latter correlation is consistent with the -.30 correlation reported in Table 7 between Attractiveness and the JPI Organization scale.

Partial set correlations. As in Study 1, set correlations were used to derive a single index of the amount of shared variance between the JPI scales and the criteria and between the NEOFFI scales and the criteria. The shrunken partial set correlation (with gender removed) for the JPI scales was .95 $(p<.001)$. The corresponding value for the NEO-FFI scales was .63 ( $p$ $<.01)$. This translates to a difference in criterion variance accounted for of $50.0 \%$ in favor of the JPI trait measures.

\section{Predictors and Incremental Validity}

As in Study 1, the set of lower level trait scales was initially searched using stepwise regression for significant predictors of the criterion variables ( the predictor reliabilities, shown in Table 6 , were first used to disattenuate the predictor-criterion correlations, shown in Tables 7 and 8 ). Big Five personality factor scales were then sought that increased the degree of criterion prediction already achieved with the lower level predictors. The reverse case was also evaluated, in which the factor-based scales were entered into the prediction equations first, followed by the trait scales. Again, the size of alpha used in deciding whether a predictor contributed significantly to prediction differed according to the set of predictors being assessed. The 5 NEOFFI predictors were evaluated at $p<.05$, whereas the 15 JPI predictors were evaluated at $p<.0167$.

Incremental validity of the NEO-FFI scales. Table 9 summarizes the results of the first set of regression analyses designed to evaluate the incremental validity of the personality factor predictors. The first two columns of Table 9 show the increases in multiple correlations (shrunken) with the criteria as the predictors added to the regression equations. The first column indicates the effects on the multiple correlations of adding specific lower level JPI scales into the prediction equations. The second column records the results of further adding certain higher level NEO-FFI scales into the regressions. Finally, the third column shows the amounts of criterion variance explained by the addition of the aforementioned significant NEO-FFI measures into the prediction equations.

Table 9 reveals that the JPI trait pool of lower level personality predictors yielded significant $(p<.0167)$ increases in the prediction of 11 of the 14 criteria (column 1). Subsequently searching the Big Five factor pool resulted in further increases $(p<$ .05 ) to the prediction of 8 criteria (column 2). The mean additional criterion variance accounted for by the Big Five factors in predicting those 8 criteria was $4.3 \%$, or $2.5 \%$ if averaged across all 14 criteria (column 3 ).

Incremental validity of the JPI scales. In the next set of analyses, the order of variable entry into the regression equations was changed. The NEO-FFI scales were first added to the equations to determine their levels of criterion predictiveness (with gender partialed). Next, the JPI scale scores were added to determine whether any lower level trait could increase criterion prediction beyond that of the Big Five factors.

The results of the regression analyses, shown in Table 10 , indicate that the NEO-FFI Big Five factor measures were able to add significantly $(p<.05)$ to the prediction of 11 of the 14 criteria (column 1). Moreover, adding the JPI trait measures into the equations further increased prediction $(p<.0167)$ of 11 criteria (column 2). The amount of additional criterion variance explained by the lower level traits, vis-à-vis the Big Five factors, averaged $13.6 \%$ across those 11 criterion variables, or $10.7 \%$ if averaged across all 14 criteria (column 3 ).

Bipartial set correlations. As in Study 1, bipartial set correlations were used to determine the incremental validity of the lower level trait measures and the higher level factor measures with the criterion set as a whole. The shrunken bipartial set correlation between the criteria (with gender partialed) and the 
Table 9

Multiple Correlations $R$ (Shrunken) in Predicting Criterion Variables With JPI Scale Scores and NEO-FFI Scale Scores (Gender Partialed)

\begin{tabular}{|c|c|c|c|}
\hline \multirow[b]{2}{*}{ Criterion } & \multicolumn{2}{|l|}{ Predictor } & \multirow[b]{2}{*}{$\%$ change $^{c}$} \\
\hline & $\mathrm{JPI}^{\mathrm{e}}$ & $\mathrm{JPI}+\mathrm{NEO}^{\mathrm{b}}$ & \\
\hline Grade point average & & $20(+0)$ & $4.1^{*}$ \\
\hline $\begin{array}{l}\text { Dating frequency } \\
\text { Dating variety }\end{array}$ & $39(-\mathrm{Ia})$ & & \\
\hline Smoking rating & $\begin{array}{l}39(-\mathrm{Ia}) \\
67(+\mathrm{Es},+\mathrm{Cp},+\mathrm{Sp},-\mathrm{Or})\end{array}$ & $\begin{array}{l}44(+\mathrm{E}) \\
70(-C+0)\end{array}$ & $4.1^{*}$ \\
\hline Smoking amount & $74(+E s,+T o,-E n,+C p,+S p)$ & $76(+0)$ & $2.7^{*}$ \\
\hline Liberal arts study & $34(+\mathrm{To})$ & $38(-C)$ & $3.5^{*}$ \\
\hline Fraternity interest & $33(+\mathrm{Cf})$ & & \\
\hline Traffic violations & 39 (-To) & $45(-E)$ & $4.9^{*}$ \\
\hline Religiosity & $52(+\mathrm{Vo})$ & & \\
\hline Attractiveness & 45 (-En, -Or) & & \\
\hline Intelligence & $34(+C p)$ & & \\
\hline Popularity & & $29(+\mathrm{A})$ & $8.1^{* *}$ \\
\hline Honesty & $34(-\mathrm{In},+\mathrm{Ax})$ & & \\
\hline $\operatorname{Sex}^{d}$ & $45(+\mathrm{Re},+\mathrm{Sp})$ & $48(+C)$ & $3.1^{*}$ \\
\hline
\end{tabular}

Note. Decimals in $R$ values are omitted. JPI $=$ Jackson Personality Inventory; NEO-FFI $=$ NEO FiveFactor Inventory.

a Blank cell means no JPI scale significantly increased $R$ at $p<.0167$. Significant JPI scales are shown in parentheses: $\mathrm{Ax}=$ Anxiety; En = Energy Level; Es = Self-Esteem; $\mathrm{Cf}=$ Conformity; $\mathrm{Cp}=$ Complexity; Ia = Interpersonal Affect; In = Innovation; Or = Organization; Re = Responsibility; Sp = Social Participation; To = Tolerance; Vo $=$ Value Orthodoxy.

${ }^{b}$ Blank cell means no NEO scale significantly increased $R$ at $p<.05$. Significant NEO scales are shown in parentheses: $\mathrm{A}=$ Agreeableness; $\mathrm{C}=$ Conscientiousness; $\mathrm{E}=$ Extraversion; $\mathrm{O}=$ Openness to Experience. ${ }^{c}$ Percentage change in criterion variance accounted for by the addition of the NEO predictors to the JPI predictors.

d Participant gender is not partialed.

$* p<.05$. ** $p<.0167$.

NEO-FFI scales (with the JPI scales partialed) was .00. (Again, the shrinkage correction reduced an otherwise positive correlation to zero.) The corresponding value for the JPI scales (with the NEO-FFI scales partialed) was $.85(p<.001)$. The resultant difference in criterion variance accounted for was $73.1 \%$ favoring the JPI scales.

Summary. Summarizing the results of the present regression analyses, both the variance of the common personality factors and the variance of the individual personality traits separately predicted the majority of the criteria of this study. Furthermore, removing either of these sources of variance out of the other still left residual variation in the predictors that was correlated with the criteria. However, the incremental validities of the higher level factor measures and the lower level trait measures relative to each other were not equivalent. Partialing the variance due to the narrow personality traits out of the Big Five factors left some amount of variation in the predictors that was correlated with the criteria, as seen in Table 9. But, partialing the variance due to the factors out of the traits left, on average, substantially more variation in the predictors that was criterion predictive, as seen in Table 10.

\section{General Discussion}

The studies reported in this article evaluated aspects of the hierarchical model of personality structure shown in Figure 1.
Specifically, the criterion predictiveness of higher level personality factors, the Big Five factors in this case, and lower level personality traits were compared. Results of correlation and regression analyses indicated that measures of both the higher and lower level personality dimensions demonstrated predictiveness with regard to the present criteria, but in an additive sense, the relatively narrow, lower level traits generally increased the criterion predictiveness of the broader, higher level factors more than the factors increased the predictiveness of the traits. These results largely replicated across two independent data sets, in which two different domains of lower level traits were evaluated using two different samples of participants.

The present findings have two important implications for personality theory and assessment. First, the fact that the components of the two levels of the personality hierarchy evaluated (i.e., the Big Five factors and their constituent traits) both showed evidence of predictiveness with regard to important behavior criteria lends support to the viability of the model itself. Note that a failure to find such evidence would not automatically invalidate the model because the criteria chosen could be unrelated to the predictors in the population or the personality measures used could be psychometrically unsound. But such negative results might eventually lead to reasonable questions about the model's veridicality.

The second implication of the present results for personality psychology concerns the finding of differences in the relative 
Table 10

Multiple Correlations $R$ (Shrunken) in Predicting Criterion Variables With NEO-FFI Scale Scores and JPI Scale Scores (Gender Partialed)

\begin{tabular}{|c|c|c|c|}
\hline \multirow[b]{2}{*}{ Criterion } & \multicolumn{2}{|c|}{ Predictor } & \multirow[b]{2}{*}{$\%$ change $^{c}$} \\
\hline & $\mathrm{NEO}^{\mathrm{a}}$ & $\mathrm{NEO}+\mathrm{JPI}^{\mathrm{b}}$ & \\
\hline $\begin{array}{l}\text { Grade point average } \\
\text { Dating frequency }\end{array}$ & $20(+0)$ & $31(+\mathrm{Re})$ & $5.8^{*}$ \\
\hline Dating variety & $20(-N)$ & $39(-\mathrm{Ia})$ & $11.7^{* *}$ \\
\hline Smoking rating & $54(+\mathrm{E},-\mathrm{C},+\mathrm{O},-\mathrm{A})$ & $68(+\mathrm{Sp},+\mathrm{To})$ & $16.8 * * *$ \\
\hline Smoking amount & $43(+O,+E)$ & $74(-\mathrm{En},+\mathrm{Es},+\mathrm{To},+\mathrm{Sp})$ & $36.1 * * *$ \\
\hline Liberal arts study & $23(+0)$ & $36(+\mathrm{To})$ & $7.8 * *$ \\
\hline Fraternity interest & & $33(+\mathrm{Cf})$ & $10.9^{* *}$ \\
\hline Traffic violations & $24(-E)$ & $45(-$ To $)$ & $14.5^{* * *}$ \\
\hline Religiosity & $27(-0)$ & $54(+\mathrm{Vo})$ & $21.6^{* * *}$ \\
\hline Attractiveness & $40(-\mathrm{C},-\mathrm{O})$ & & \\
\hline Intelligence & & $34(+C p)$ & $11.2^{* *}$ \\
\hline Popularity & $29(+\mathrm{A})$ & & \\
\hline Honesty & $27(-0)$ & $37(+\mathrm{Ia})$ & $6.8 * *$ \\
\hline $\operatorname{Sex}^{\mathrm{d}}$ & $37(+\mathrm{C},+\mathrm{E})$ & $45(+\mathrm{Re})$ & $6.4^{* *}$ \\
\hline
\end{tabular}

Note. $\quad$ Decimals in $R$ values are omitted. NEO-FFI = NEO Five-Factor Inventory; JPI = Jackson Personality Inventory.

${ }^{a}$ Blank cell means no NEO scale significantly increased $R$ at $p<.05$. Significant NEO scales are shown in parentheses: $\mathrm{A}=$ Agreeableness; $\mathrm{C}=$ Conscientiousness; $\mathrm{E}=$ Extraversion; $\mathrm{N}=$ Neuroticism; $\mathrm{O}=$ Openness to Experience.

${ }^{b}$ Blank cell means no JPI scale significantly increased $R$ at $p<.0167$. Significant JPI scales are shown in parentheses: $\mathrm{En}=$ Energy Level; $\mathrm{Es}=$ Self-Esteem; $\mathrm{Cf}=$ Conformity; $\mathrm{Cp}=$ Complexity; Ia = Interpersonal Affect; $\operatorname{Re}=$ Responsibility; $\mathrm{Sp}=$ Social Participation; To = Tolerance; Vo = Value orthodoxy.

${ }^{\mathrm{c}}$ Percentage change in criterion variance accounted for by the addition of the JPI predictors to the NEO predictors.

${ }^{\mathrm{D}}$ Participant gender is not partialed.

${ }^{*} p<.05 .{ }^{* *} p<.0167$. ${ }^{* * *} p<.001$.

predictive merits of the higher and lower level personality dimensions, differences that favored the latter. This outcome bears on the increasingly common practice in research to assess personality with Big Five factors measures only, eschewing the assessment of those factors' lower level components. If in the present studies only the NEO-FFI factor-based predictors had been used, a certain measure of criterion prediction would indeed have been achieved. Adding the PRF or JPI trait predictors to the prediction equations, however, increased the correlations substantially in most cases. This finding is consistent with the argument that combining narrow personality traits into their underlying broad factors can entail predictive losses, losses that are due to the ensuing elimination of trait-specific but criterion-valid variance (Ashton et al., 1995; Hough, 1992; Paunonen, 1993; Paunonen et al., 1992, in press; Schneider, Hough, \& Dunnette, 1996; Schönemann, 1990).

\section{On Common and Specific Trait Variance}

It is clear from the results of this research that the personality trait measures showed good levels of incremental predictive validity vis-à-vis the personality factor measures. But is the interpretation of that finding correct - that the specific variance of the traits is as important, or more important, for prediction as is their common variance? The accuracy of such a conclusion depends in part on empirical associations existing between the assessed lower level traits and higher level factors. It was assumed in the present studies that when the NEO-FFI scales were partialed out of the PRF and JPI trait scales, the common variance underlying those traits was partialed, allowing for a test of the predictive abilities of their specific variance components. But are the present lower level trait measures in fact related to the higher level factor measures?

There are good reasons to believe that the model illustrated in Figure 1 is probably a fair representation of the personality variables evaluated in these studies. These reasons are based on past factor analytic studies of the present lower level traits, studies that have amply documented the traits' close allegiances to the Big Five domain. The factors of both the PRF scales and the JPI scales have been evaluated in this context.

With regard to the factors underlying the PRF, many independent studies have shown its scales to fit well within the fivefactor space (e.g., Costa \& McCrae, 1988; Paunonen et al., 1992; Stumpf, 1993), with only small anomalies pertaining to the make-up of the Conscientiousness factor (Jackson, Paunonen, Fraboni, \& Goffin, 1996). Furthermore, the PRF-NEOFFI correlations shown in Table 1 are remarkably similar to the factor loadings of the PRF traits on Big Five factors reported by Costa and McCrae (1988). In fact, if one compares the highest correlation for each personality trait in Table 1 with that trait's highest factor loading in Costa and McCrae's Table 4, 16 out of 21 traits define the same Big Five dimension in both 
studies. The other five traits tended to split across more than one factor in both data sets, but still come close to meeting the same standard of replication.

The JPI scales have also been placed into the space of the Big Five. In a recent cross-replication analysis of 10 independent data sets, Paunonen and Jackson (1996) found strong JPI factors that bore close resemblances, both subjectively and objectively, to the Big Five. Moreover, the JPI (mean) factor structure reported in Table 1 of that study is strikingly similar to the JPINEO-FFI correlation matrix shown in the present Table 6. For instance, the Big Five factor on which each JPI scale was found to be most salient in Paunonen and Jackson's study is the same factor on which that scale had its highest correlation in this study.

Note, however, that Paunonen and Jackson's (1996) results led those authors to the conclusion that the JPI scales of Energy Level, Risk Taking, and Value Orthodoxy do not well define the five-factor space (see also Table 6). The implication of that finding for this research is that any predictive gains by those three JPI variables over the NEO-FFI Big Five measures might not have been due just to those traits' specific variances, but to their specific plus common (i.e., common to some factor or factors independent of the Big Five) variance components. But examination of Table 10 shows that those three JPI scales were not recurrent contributors to the incremental validities of the lower level traits in this research. Energy Level and Value Orthodoxy each added to the Big Five's prediction of only one criterion, and Risk Taking showed no incremental utility in the present context.

In summary, it is maintained that most of the lower level personality traits assessed in this research have strong links to the Big Five personality factors. Thus, the empirical evaluations of incremental validity are interpreted as proper indications of the degree to which different components of trait variance contributed to criterion prediction. The common variance underlying the lower level traits, variance attributable to the Big Five factors of personality in this case, is certainly important to the prediction of behavior. But to overlook the supplementary information contained in the traits' specificities is to forego even greater levels of predictive accuracy.

\section{Generalizability of the Present Results}

The present studies have certain limitations that bear on the generalizability of their results. Those results are, to some extent, dependent on the psychological variables chosen for study. They are also partly dependent on the participant samples assessed.

\section{Effect of Variables Studied}

To what extent are the present results dependent on the specific psychological variables selected for study? With regard to the criteria, it is obvious that the results pertain to those variables, and to those variables alone. Although it was found that the lower level traits generally, but not always, outpredicted their higher level factors, a different set of criterion variables could have yielded the opposite outcome. This contrary outcome might be especially likely if, as suggested earlier, criteria were selected to represent a set of factor-based personality variables.

With regard to the generalizability of the predictors used, it could be argued that the present results are independent of the higher level personality variables selected for analysis, because supposedly no selection was involved. These personality dimensions, the Big Five factors, are presumed to constitute the entire universe of variables at the top level of the personality hierarchy (cf. Block, 1995; Jackson et al., 1996; Mershon \& Gorsuch, 1988; Paunonen \& Jackson, 1996). Of course, if that presumption is incorrect, if for example there are actually more personality factors than the Big Five, then using those other dimensions as criterion predictors could yield results at variance with those reported in this article.

It could also be argued that the present results are mostly independent of the lower level personality traits used, because they can be thought of as just one of many randomly parallel sets of Big Five exemplars selected from the five-factor universe. Certainly there exists a multitude of different lower level trait variables representing the Big Five, each with its own component of trait-specific variance, variance that might or might not be predictive of the present criteria. Nevertheless, although those different lower level traits could yield different results in the prediction of specific criteria, the overall pattern of results could be the same as that found here. Consider that the PRF traits of Study 1 did not always predict the same variables as did the JPI traits of Study 2. But the overall findings of both studies led to the same conclusion: that relatively narrow, lower level traits, in general, add nonredundant information to their higher level personality factors in the prediction of diverse behavioral criteria.

\section{Effect of Participants Tested}

To what extent are the present findings dependent on the samples of participants assessed? Although the general outcome indicating the superiority of the lower level traits over the higher level factors in criterion prediction was observed in both studies, it is apparent that some of the specific results that can be compared directly across the two studies did not replicate. In particular, many of the NEO-FFI scales that were strong criterion predictors in the first sample (Table 3) were not strong predictors of the same criteria in the second sample (Table 8 ). This lack of replication could be due to undue amounts of error variance in the predictor or criterion variables. ${ }^{2}$ The lack of replication could

\footnotetext{
${ }^{2}$ It is acknowledged that the present lower level predictors (the PRF and JPI scales) and higher level predictors (the NEO-FFI scales) differ in ways other than just the stratum of the personality hierarchy they represent. Foremost among these differences is the fact that the items do not have the same content. Thus, it is possible that the PRF and JPI scales generally outpredicted the NEO-FFI scales in these studies because the former simply have better items and, consequently, better psychometric properties. This is considered an unlikely explanation for the present results. The test manuals for the PRF (Jackson, 1984), the JPI (Jackson, 1994), and the NEO-FFI (Costa \& McCrae, 1992c) abundantly document empirical evaluations supporting those instruments' reliability, construct validity, and freedom from response bias. There is, furthermore, no obvious reason why data for the latter instrument should be deficient specifically in the present studies.
} 
also be due to relatively small sample sizes producing Type I errors. That is to say, there may in fact be no relation between the predictor variables and the criterion variables in the population, but the relatively small samples could have yielded unstable estimates of population correlations that were sometimes significant by chance alone. Note that this explanation posits that the personality dimensions measured by the NEO-FFI are not determinants of the criteria used in these studies, which implies that no Big Five personality factor is associated with variables such as smoking behavior, religiosity, and dating behavior.

If the Big Five factors are actually uncorrelated with the present criteria in the population, what are the implications for the expected replicabilities of the PRF and JPI correlations reported in this article? Recall it was concluded that these lower level trait scales predicted the criteria partly because of their common (Big Five) factor variance and partly because of their trait-specific variance. But if the population correlations between the Big Five and the criteria are all zero, then cross-validation of the PRF and JPI predictors should, as with the NEO-FFI predictors, also result in a general decrease in predictiveness across those traits. This is because the common variance of the present lower level scales would have been predictive in the present studies only by chance and would not be likely to replicate. Whether the specific variance of the lower level traits would remain predictive under crossvalidation is a separate question.

Unfortunately, it cannot be ascertained with the present data whether the lower level trait measures would maintain their predictiveness on cross-validation any better than did the higher level factor measures. The clear theoretical interpretability of some of the PRF and JPI predictor-criterion relations found in these studies, however, suggests that not all of them are spurious. Moreover, given the diversity of the content coverage of the present predictor variables, it seems implausible that the PRF and JPI personality traits and the Big Five personality factors are in actuality uncorrelated with the present heterogeneous set of behavior criteria.

\section{Predetermined Prediction Results}

The issue concerning the relative predictive merits of narrow, lower level traits and broad, higher level factors should, in certain empirical applications, never even arise. Depending on the variables involved and the method of analysis, it may be possible to specify a priori which will win a statistical prediction contest. In most cases, however, explicit empirical comparisons of predictive accuracy are warranted.

\section{Effects of Variable Selection}

Goldberg (1993) has correctly observed that, in any regression analysis, an aggregated measure will never be a better predictor of a criterion variable than will that aggregate's component variables. This is because variance specific to the component variables, which is lost in the process of combining those variables into the aggregate, can only add to prediction (or leave it unchanged) and not detract from it. Thus, lower level trait measures will always outpredict higher level factor measures if (a) the latter are derived arithmetically as weighted (excluding regression weighted) or unweighted composites of the former, and (b) the two sets of measures are then compared in multiple regression analyses of the type described, for example, in this article.

An example of the circumstance in which lower level predictors are guaranteed to outpredict higher level predictors can be found in Mershon and Gorsuch's (1988) study. Those authors compared the 16 individual scales of the 16 Personality Factor Questionnaire (Cattell, Eber, \& Tatsuoka, 1970) with the 6 factors underlying those scales in the prediction of various reallife criteria, such as worker pay, marijuana usage, and psychiatric status. As expected, their results confirmed the fact that the specific variance of the lower level personality scales must add to criterion prediction above and beyond that of the common variance contained in the higher level factors of those scales. What was unexpected about Mershon and Gorsuch's data, however, was the relatively large amount by which the lower level measures added to the higher level measures in predictionthe former roughly doubled the amount of criterion variance explained by the latter. From a cost-benefit point of view, that degree of increased accuracy in predicting a criterion might be well worth any added cost of including the lower level predictors in one's research design.

The foregone conclusion regarding relative predictiveness referred to above does not apply to the present studies, because the type of aggregation described was not done. The present higher level factor variables were not constructed from the participants' responses to the lower level trait measures (see, also, Ones et al., 1994). Instead, the two classes of variables were assessed independently, using two different batteries of measures, yielding two different sets of data. Thus, it is entirely possible for the present Big Five factor measures to have specific variance of their own, variance independent of the lower level trait measures' commonality and yet predictive of any number of criterion variables. Indeed, the factors of the present studies did show some measure of incremental validity in relation to the traits, as seen in Tables 4 and 9.

\section{Effects of Variable Dimensionality}

Does the complexity or dimensionality of variables predetermine relative predictive accuracy? Although it may be reasonable to expect that a match in the factorial complexity of predictor and criterion will result in optimal prediction and a mismatch in suboptimal prediction (Ones \& Viswesvaran, 1996), neither outcome necessarily follows. No formal proof is needed for the assertion that a unidimensional predictor could either correlate perfectly with or be orthogonal to a unidimensional criterion. Nor is any needed for the statement that a multidimensional predictor might similarly correlate perfectly with or be orthogonal to a multidimensional criterion, their resultant correlation being dependent on the interrelations of all the individual dimensions involved.

What about the correlation expected between a unidimensional predictor and a multidimensional criterion (or the reverse)? The single dimension of the predictor could be one of the multiple dimensions of the criterion or it could be an orthogonal dimension; thus, the correlation could be relatively high or it could be zero. The present lower level PRF and JPI predictors 
were certainly constructed to be homogeneous measures of unidimensional personality traits. The criteria, in contrast, arguably represent measures of multidetermined and multidimensional behaviors. But, as seen in Tables 2 and 7, some of those unidimensional predictors correlated quite highly with some of those multidimensional criteria. Ashton et al. (1995) have reported some similar results. The point is that empirical evaluations of predictiveness are not obviated simply because predictors and criteria are, or are not, of equal dimensionality.

In a recent discussion of personality predictors and factorial complexity, Ones and Viswesvaran (1996) found it "puzzling" how the expectation has come about that "increased factorial purity in the personality predictor lead [s] to higher correlations with factorially complex and heterogeneous criteria'" (p. 616). But this expectation should not be puzzling at all because, as observed in the preceding paragraphs, the factorially pure predictor might be measuring one of the criterion variable's facets. And, combining that unidimensional predictor with others into a broad composite predictor could decrease prediction if those other predictors are unrelated or negatively related to the facets of the criterion. (For extended discussions of issues raised by Ones \& Viswesvaran, 1996, see Ashton, in press; Hogan \& Roberts, 1996; Paunonen et al., in press; Schneider et al., 1996).

Nunnally (1978) has offered what this author considers to be unimpeachable advice on optimizing the prediction of multidimensional variables:

As some will argue, the criterion usually is factorially complex and consequently can be predicted best by a factorially complex predictor test. Instead of building the factorial complexity into a particular test, it is far better to meet the factorial complexity by combining tests in a battery by multiple regression, in which case tests would be selected to measure the different factors that are thought to be important. (p. 268)

Nunnally (1978) described several advantages that this empirical approach has for the prediction and explanation of behavior (pp. 267-270). Two are seen as particularly important in the present context. First, because the individual predictors are used together in a multiple regression analysis, the specific variance of each predictor has the opportunity of increasing criterion prediction over that achieved by the variance preserved in any composite. Second, being homogeneous variables of known compositions, those same predictors can be used to scale the test respondents in terms of their standing on important psychological constructs. In short, Nunnally recognized that aggregating a heterogeneous set of variables into a multidimensional predictor can entail predictive losses and result in respondent scores having little psychological meaning. ${ }^{3}$ The present research represented an empirical evaluation of Nunnally's propositions, and the results can be interpreted as yielding strong support for his advice on measurement and prediction methods in psychology.

\footnotetext{
${ }^{3}$ The same problems do not apply if the variables aggregated represent psychometrically parallel measures of the same construct. As demonstrated empirically (e.g., Jackson \& Paunonen, 1985; Paunonen \& Gardner, 1991; Paunonen \& Jackson, 1985), psychometric theory correctly predicts that such aggregation leads to improvements in both the prediction of criteria and the measurement of underlying psychological characteristics.
}

\section{References}

Ashton, M. C. (in press). Personality and job performance: The importance of narrow traits. Journal of Organizational Behavior.

Ashton, M. C., Jackson, D. N., Paunonen, S. V., Helmes, E., \& Rothstein, M. G. (1995). The criterion validity of broad factor scales versus specific trait scales. Journal of Research in Personality, 29, 432 442.

Barrick, M. R., \& Mount, M. K. (1991). The Big Five personality dimensions and job performance: A meta-analysis. Personnel Psychology, 44, 1-26.

Block, J. (1995). A contrarian view of the five-factor approach to personality description. Psychological Bulletin, 117, 187-215.

Cattell, R. B., Eber, H. W., \& Tatsuoka, M. (1970). Handbook for the Sixteen Personality Factor Questionnaire. Champaign, IL: Institute for Personality and Ability Testing.

Cattell, R. B., \& Krug, S. E. (1986). The number of factors in the 16PF: A review of the evidence with special emphasis on methodological problems. Educational and Psychological Measurement, 46, 509522.

Cohen, J., \& Cohen, P. (1983). Applied multiple regression/correlation analysis for the behavioral sciences. New York: Erlbaum.

Costa, P. T., Jr., \& McCrae, R. R. (1988). From catalog to classification: Murray's needs and the five-factor model. Journal of Personality and Social Psychology, 55, 258-265.

Costa, P. T., Jr., \& McCrae, R. R. (1992a). Four ways five factors are basic. Personality and Individual Differences, 13, 653-665.

Costa, P. T., Jr., \& McCrae, R. R. (1992b). Reply to Eysenck. Personality and Individual Differences, 13, 861-865.

Costa, P. T., Jr., \& McCrae, R. R. (1992c). Revised NEO Personality Inventory (NEO-PI-R) and NEO Five-Factor Inventory (NEO-FFI) professional manual. Odessa, FL: Psychological Assessment Resources.

Costa, P. T., Jr., \& McCrae, R. R. (1995). Domains and facets: Hierarchical personality assessment using the revised NEO Personality Inventory. Journal of Personality Assessment, 64, 21-50.

Cronbach, L. J., \& Meehl, P. (1955). Construct validity in psychological tests. Psychological Bulletin, 52, 281-302.

Digman, J. M. (1990). Personality structure: Emergence of the fivefactor model. Annual Review of Psychology, 41, 417-440.

Eysenck, H. J. ( 1947). Dimensions of personality. London: Routledge \& Kegan Paul.

Eysenck, H. J. (1992a ). Four ways five factors are not basic. Personality and Individual Differences, 13, 667-673.

Eysenck, H. J. (1992b). A reply to Costa and McCrae: P or A and CThe role of theory. Personality and Individual Differences, 13, 867868.

Goldberg, L. R. (1972). Parameters of personality inventory construction and utilization: A comparison of prediction strategies and tactics. Multivariate Behavioral Research Monographs, 72(2).

Goldberg, L. R. (1993). The structure of personality traits: Vertical and horizontal aspects. In D. C. Funder, R. D. Parke, C. TomlinsonKeasey, \& K. Widaman (Eds.), Studying lives through time: Personality and development (pp. 169-188). Washington, DC: American Psychological Association.

Hampson, S. E., John, O. P., \& Goldberg, L. R. (1986). Category breadth and hierarchical structure in personality: Studies of asymmetries in judgments of trait implications. Journal of Personality and Social Psychology, 51, 37-54.

Hase, H. D., \& Goldberg, L. R. (1967). The comparative validity of different strategies of deriving personality inventory scales. Psychological Bulletin, 67, 231-248.

Hogan, J., \& Roberts, B. W. (1996). Issues and non-issues in the fidelity-bandwidth trade-off. Journal of Organizational Behavior, 17, 627-637. 
Hough, L. M. (1992). The "Big Five" personality variables-construct confusion: Description versus prediction. Human Performance, 5, $139-155$.

Jackson, D. N. (1976). Jackson Personality Inventory manual. Port Huron, MI: Research Psychologists Press.

Jackson, D. N. (1977). Reliability of the Jackson Personality Inventory. Psychological Reports, 40, 613-614.

Jackson, D. N. (1984). Personality Research Form manual. Port Huron, MI: Research Psychologists Press.

Jackson, D. N. (1994). Jackson Personality Inventory-Revised manual. Port Huron, MI: Sigma Assessment Systems.

Jackson, D. N., \& Paunonen, S. V. (1985). Construct validity and the predictability of behavior. Journal of Personality and Social Psychology, 49, 554-570.

Jackson, D. N., Paunonen, S. V., Fraboni, M., \& Goffin, R. G. (1996). A five-factor versus a six-factor model of personality structure. Personality and Individual Differences, 20, 33-45.

John, O. P. (1990). The "Big Five" factor taxonomy: Dimensions of personality in the natural language and in questionnaires. In L. A. Pervin (Ed.), Handbook of personality: Theory and research (pp. 66-100). New York: Springer-Verlag.

McCrae, R. R., \& Costa, P. T., Jr. (1992). Discriminant validity of the NEO-PI-R facet scales. Educational and Psychological Measurement, 52, 229-237.

McCrae, R. R., \& John, O. P. (1992). An introduction to the five-factor model and its applications. Journal of Personality, 60, 175-215.

Mershon, B., \& Gorsuch, R. L. (1988). Number of factors in the personality sphere: Does increase in factors increase the predictability of real-life criteria? Journal of Personality and Social Psychology, 55, 675-680.

Murray, H. A. (1938). Explorations in personality. New York: Oxford Press.

Nunnally, J. C. (1978). Psychometric theory. New York: McGraw-Hill.

Ones, D. S., Schmidt, F. L., \& Viswesvaran, C. (1994, April). Do broader personality variables predict job performance with higher validity? Paper presented at the Conference of the Society for Industrial and Organizational Psychology, Nashville, TN.

Ones, D. S., \& Viswesvaran, C. (1996). Bandwidth-fidelity dilemma in personality measurement for personnel selection. Journal of Organizational Behavior, 17, 609-626.

Paunonen, S. V. (1993, August). Sense, nonsense, and the Big Five factors of personality. Paper presented at the 101st Annual Convention of the American Psychological Association, Toronto, Ontario, Canada.

Paunonen, S. V., \& Gardner, R. C. (1991). Biases resulting from the use of aggregated variables in psychology. Psychological Bulletin, $109,520-523$

Paunonen, S. V., \& Jackson, D. N. (1985). The validity of formal and informal personality assessments. Journal of Research in Personality, 19, 331-342.

Paunonen, S. V., \& Jackson, D. N. (1996). The Jackson Personality Inventory and the Five-Factor Model of personality. Journal of Research in Personality, 30, 42-59.

Paunonen, S. V., Jackson, D. N., Trzebinski, J., \& Forsterling, F. (1992). Personality structure across cultures: A multimethod evaluation. Journal of Personality and Social Psychology, 62, 447-456.

Paunonen, S. V., Rothstein, M. G., \& Jackson, D. N. (in press). Narrow reasoning about the use of broad personality measures in personnel selection. Journal of Organizational Behavior.

Schneider, R. J., Hough, L. M., \& Dunnette, M. D. (1996). Broadsided by broad traits: How to sink science in five dimensions or less. Journal of Organizational Behavior, 17, 639-655.

Schönemann, P. H. (1990). Facts, fictions, and common sense about factors and components. Multivariate Behavioral Research, 25, 4751.

Smith, G. M. (1969). Relations between personality and smoking behavior in preadult subjects. Journal of Consulting and Clinical Psychol ogy, 33, 710-715.

Stumpf, H. (1993). The factor structure of the Personality Research Form: A cross-national evaluation. Journal of Personality, 61, 2748.

Tett, R. P., Jackson, D. N., \& Rothstein, M. G. (1991 ). Personality measures as predictors of job performance: A meta-analytic review. Personnel Psychology, 44, 703-742.

Velicer, W. F., Govia, J. M., Cherico, N. P., \& Corriveau, D. P. (1985). Item format and the structure of the Buss-Durkee Hostility Inventory. Aggressive Behavior, 11, 65-82.

Velicer, W. F., \& Stevenson, J. F. (1978). The relation between item format and the structure of the Eysenck Personality Inventory. Applied Psychological Measurement, 2, 293-304.

Received February 26, 1996

Revision received March 20, 1997

Accepted March 29, 1997 